Check for updates

Cite this: RSC Adv., 2017, 7, 55582

Received 25th October 2017

Accepted 30th November 2017

DOI: $10.1039 / c 7 r a 11773 f$

rsc.li/rsc-advances

\section{Achieving a high-efficiency dual-core chromophore for emission of blue light by testing different side groups and substitution positions $\uparrow$}

\author{
Hwangyu Shin, $\dot{t}^{\mathrm{b}}$ Beomjin Kim, $\dot{t}^{\mathrm{a}}$ Hyocheol Jung, ${ }^{\mathrm{a}}$ Jaehyun Lee, ${ }^{\mathrm{b}}$ Hayoon Lee, ${ }^{\mathrm{a}}$ \\ Seokwoo Kang, a Jiwon Moon, 'Joonghan Kim iD b and Jongwook Park (iD *a
}

\begin{abstract}
Hetero dual-core derivatives that combine anthracene and pyrene were systematically studied for the purpose of producing highly efficient blue light-emitting materials applicable to organic light-emitting diode (OLED) lighting. Five compounds were designed in order to (1) determine which one of the two core chromophores in a hetero dual-core moiety, if any, acts as the main contributor to the optical and electronic properties of the final compounds, (2) control the electron-donating ability of the side group, and (3) change the substitution position. $1-\left[1,1^{\prime} ; 3^{\prime}, 1^{\prime \prime}\right]$ terphenyl-5'-yl-6- $\left(10-\left[1,1^{\prime} ; 3^{\prime}, 1^{\prime \prime}\right]\right.$ terphenyl-5'-ylanthracen-9-yl)-pyrene (TP-AP-TP) was used as the reference material, and four other materials, including diphenyl-[10-(6-[1,1'; $\left.3^{\prime}, 1^{\prime \prime}\right]$ terphenyl-5'-yl-pyren-1-yl)-anthracen-9-yl]-amine (DPA-AP-TP), diphenyl-[6-(10-[1,1'; $\left.3^{\prime}, 1^{\prime \prime}\right]$ terphenyl-5'-yl-anthracen-9-yl)-pyren-1-yl]-amine (TP-AP-DPA), diphenyl-\{4[10- $\left(6-\left[1,1^{\prime} ; 3^{\prime}, 1^{\prime \prime}\right]\right.$-terphenyl-5'-yl-pyren-1-yl)-anthracen-9-yl]-phenyl\}-amine (TPA-AP-TP) and diphenyl$\left\{4-\left[6-\left(10-\left[1,1^{\prime} ; 3^{\prime}, 1^{\prime \prime}\right]\right.\right.\right.$ terphenyl-5'-yl-anthracen-9-yl)-pyren-1-yl]-phenyl\}-amine (TP-AP-TPA), were synthesized as model compounds. The synthesized materials showed absorption wavelength peaks at 403-410 nm in the film state and exhibited PL emissions of 458-505 nm. Also, anthracene was shown to be the main core contributing to the optical and electronic properties. Among the synthesized molecules, the TPA-AP-TP molecule, in which triphenylamine, with its optimum electron-donating ability, was substituted into anthracene, showed excellent electroluminescence (EL) performance for OLED lighting with a current efficiency of $8.05 \mathrm{~cd} \mathrm{~A}^{-1}$, external quantum efficiency of $6.75 \%$, and narrow EL FWHM of $53 \mathrm{~nm}$.
\end{abstract}

\section{Introduction}

Organic light-emitting diodes (OLEDs) have attracted considerable attention in both academic and industrial circles since the pioneering work of Tang and Vanslyke in 1987. Because of advantageous properties such as self-emission, full-color emission, low driving voltage, flexibility and fast response time, OLEDs have recently been developed and applied extensively in the small and medium display market, and many studies are underway for their applications in television and lighting. ${ }^{1}$ Certain properties of OLEDs make them especially attractive in the lighting market, including area emission characteristics not found for other existing sources of light, environmentally friendly efficient use of energy, large area, ultra-light weight,

\footnotetext{
${ }^{a}$ Department of Chemical Engineering, Kyung Hee University, Gyeonggi-do, 17104, Republic of Korea.E-mail: jongpark@khu.ac.kr

${ }^{b}$ Department of Chemistry, The Catholic University of Korea, Bucheon, 420-743, Republic of Korea

$\dagger$ Electronic supplementary information (ESI) available. See DOI: $10.1039 / \mathrm{c} 7 \mathrm{ra11773f}$

\$ These authors contributed equally to this work.
}

and ultra-thin shape. It has thus become increasingly important to carry out investigations of the applications of OLEDs if they are to become the next-generation source of lighting and replace existing fluorescent and incandescent lamps. ${ }^{2}$ White OLEDs for lighting can be divided into those that produce white light by combining red-light, green-light, and blue-light (R, G, B) emitters $^{3}$ and those that produce white light by combining emitters of sky-blue light and orange light or of sky-blue light and red light. ${ }^{4}$ Investigations have been more actively pursued for the latter two-color white OLEDs whose structures are relatively simple, because low cost is regarded as important in the lighting field, unlike in the display field. In addition, since the emission spectra of organic materials generally have peaks with broader wavelengths than do the emission spectra of inorganic materials, only two types of organic emitters, in particular the emitters of sky-blue and orange light or of sky-blue and red light, need to be combined to produce white light when using OLEDs. Many studies have achieved high efficiency and long lifetime for materials that emit orange or red light, but it has been a challenge to develop materials that emit pure blue light with high efficiency because of the large difference in the energy 
levels of adjacent hole- and electron-transporting layers caused by the wide band gap. ${ }^{5}$

To overcome such issues and increase the efficiency of materials that emit blue light, most existing studies have used polycyclic aromatic hydrocarbon (PAH) moieties based on a single-core chromophore, such as anthracene, ${ }^{6}$ pyrene, ${ }^{7}$ and fluorene ${ }^{8}$ which have excellent fluorescence characteristics. Studies have been actively conducted, especially with the anthracene core, to increase color purity and electroluminescence (EL) efficiency by adjusting dihedral angles of the core of the molecule or by introducing bulky groups or electron donor and acceptor groups as side groups. ${ }^{9}$ Furthermore, the most recent studies have focused on molecules consisting of multicore chromophore structures by combining two or more of the same PAH core moieties or by combining different such moieties. ${ }^{10}$ Our group has recently reported dual-core chromophores of the "AP-core type" where anthracene and pyrene cores were directly connected. These dual-core derivatives showed outstanding performances, with the EL efficiency and device lifetime increased by more than a factor of two compared to light-emitting materials that applied anthracene or pyrene as a single-core chromophore. ${ }^{11}$ Unlike the corresponding singlecore materials, these dual-core structures displayed high efficiency because both anthracene and pyrene contributed to the absorption and emission processes. ${ }^{12}$ However, few studies on such hetero-type dual cores have been published, and there are also few published papers on the roles of core, types of side group and various substitution changes regarding on molecular structure. Accordingly, in order to develop blue light-emitting materials for highly efficient OLED lighting devices, this study examined hetero dual-core moieties in which anthracene and pyrene are connected. We specifically investigated not only which, if any, of the two core chromophores act as the main contributor to the absorption and emission processes, but also the effects of changing the side group on the performance properties of the final compounds. Therefore, (1) a hetero dualcore moiety consisting of anthracene and pyrene (AP-core) was selected as the standard core chromophore; (2) a nitrogen atom was introduced instead of a phenyl ring in order to increase electron donation to the dual core and hence increase device efficiency, (3) a bulky side group was introduced to suppress intermolecular interactions, and (4) the position at which the electron-donating side group is bonded to the dual core was changed to study the effects of changes in the substitution position on the characteristics of the material.

\section{Results and discussion}

\subsection{Molecular design, synthesis, and optical properties}

As previously reported by our group, $1-\left[1,1^{\prime} ; 3^{\prime}, 1^{\prime \prime}\right]$ terphenyl-5'-yl6-(10-[1,1'; ; $\left.3^{\prime}, 1^{\prime \prime}\right]$ terphenyl-5'-yl-anthracen-9-yl)-pyrene (TP-APTP), which includes anthracene and pyrene as a hetero dual core, yielded a better performance, with about two times higher EQE values and two times longer blue emission lifetimes than their single core counterparts. ${ }^{11}$

Moreover, oscillator strength is closely associated with the electronic transition of the molecule, and an increase of the oscillator strength indicates a contribution of greater energy to the electronic transition at that absorption wavelength. For the AP core, the oscillator strength value of anthracene was

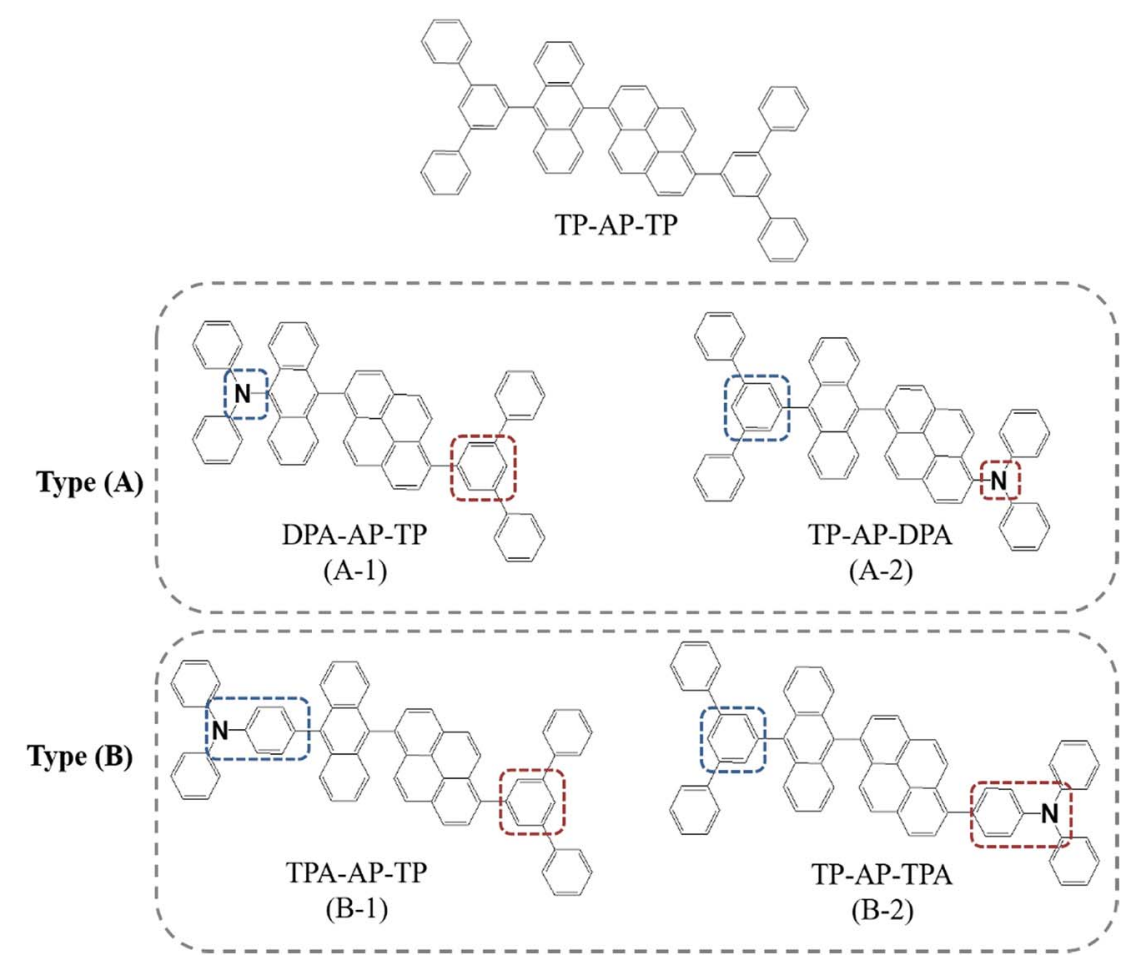

Scheme 1 The chemical structures of the synthesized light-emitting materials based on dual-core chromophores. 
Table 1 Optical and thermal properties of the synthesized compounds

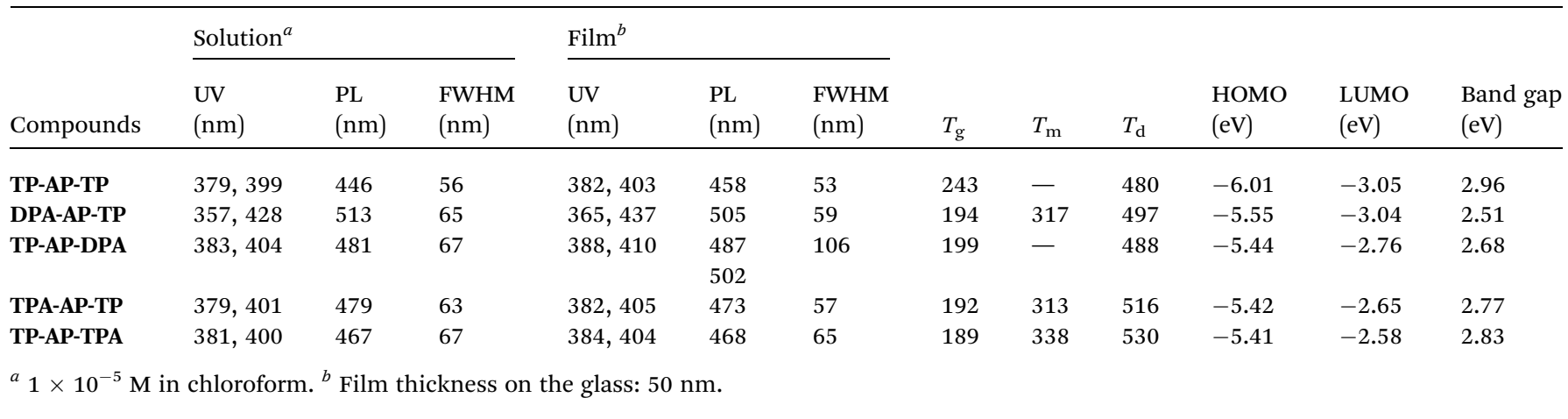

calculated to be 2.5 times greater than the oscillator strength value of pyrene. Comparing oscillator strength values indicated anthracene to be the primary core and pyrene to be the secondary core in this dual-core structure. ${ }^{12}$ The primary and the secondary cores mean the main and the secondary contributors to absorbance and emission of light.

Since anthracene is the primary core of the dual core, substitution of an electron-donating side group into anthracene is expected to yield greater changes of the intrinsic properties of the final compound compared to a substitution into pyrene.

To determine the effects of changing the substitution position of the side group, four types of molecules that introduced $m$-terphenyl, diphenylamine, and triphenylamine moieties as side groups were synthesized: diphenyl-[10-(6-[1,1 $\left.1^{\prime} ; 3^{\prime}, 1^{\prime \prime}\right]$ terphenyl-5'-yl-pyren-1-yl)-anthracen-9-yl]-amine (DPA-AP-TP), diphenyl-[6-(10-[1,1'; ; $\left.{ }^{\prime}, 1^{\prime \prime}\right]$ terphenyl-5'-yl-anthracen-9-yl)-pyren1-yl]-amine (TP-AP-DPA), diphenyl- $\left\{4-\left[10-\left(6-\left[1,1^{\prime} ; 3^{\prime}, 1^{\prime \prime}\right]\right.\right.\right.$ terphenyl-5'-yl-pyren-1-yl)-anthracen-9-yl]-phenyl\}-amine (TPA-APTP) and diphenyl- $\left\{4-\left[6-\left(10-\left[1,1^{\prime} ; 3^{\prime}, 1^{\prime \prime}\right]\right.\right.\right.$ terphenyl-5'-yl-anthracen9-yl)-pyren-1-yl]-phenyl\}-amine (TP-AP-TPA) (see Scheme 1). Diphenylamine, an electron-donating group, was substituted into the anthracene and pyrene cores to make DPA-AP-TP and TP-AP-DPA, respectively. These molecules were classified as types (A-1) and (A-2), respectively. TPA-AP-TP and TP-AP-TPA were formed by the substitution of triphenylamine, a side group in which an additional phenyl ring was added to the link between the core and diphenylamine side group in the type (A) form, and were classified as type (B-1) and (B-2), respectively. These synthesized molecules were compared with TP-AP-TP, which consists only of phenyl rings that do not include any hetero-atom. The five compounds were synthesized using boronylation and Suzuki aryl-aryl coupling reactions as illustrated in Fig. S1, $\dagger$ and the synthesized materials were characterized by nuclear magnetic resonance spectroscopy, elemental analysis, and fast atom bombardment mass analysis.

To determine the thermal properties of the synthesized molecules, thermal gravimetric analysis (TGA) and differential scanning calorimetry (DSC) were used, with the results summarized in Table 1. All of the synthesized molecules were quite thermally stable, with $T_{\mathrm{g}}$ values of at least $189^{\circ} \mathrm{C}$ and decomposition temperature $\left(T_{\mathrm{d}}\right)$ values of at least $488{ }^{\circ} \mathrm{C}$. In particular, TPA-AP-TP (B-1) and TP-AP-TPA (B-2), perhaps due to their increased molecular weights, displayed excellent $T_{\mathrm{d}}$ values of 516 and $530{ }^{\circ} \mathrm{C}$, respectively. Molecules with high $T_{\mathrm{d}}$ values have an advantage in that the morphology of the material is not easily changed by the heat generated during operation of the OLED device. ${ }^{13}$

Ultraviolet-visible (UV-vis) absorption spectra and related data of the synthesized compounds are shown in Fig. 1 and Table 1. To understand the changes in optical properties, (a)

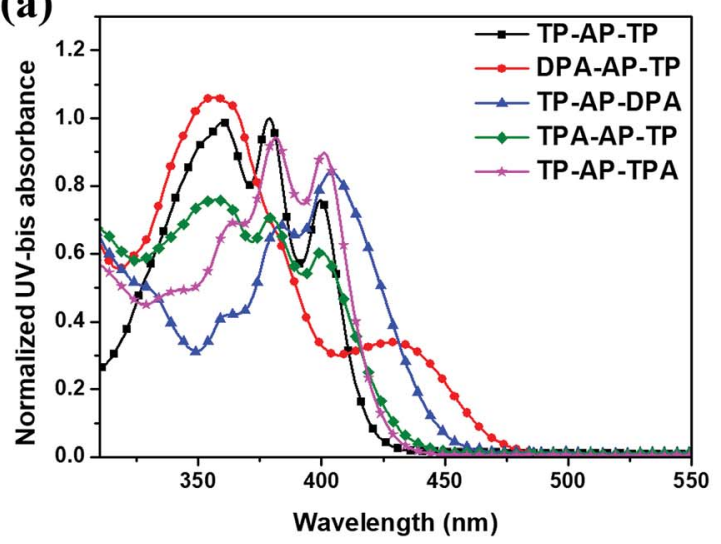

(b)

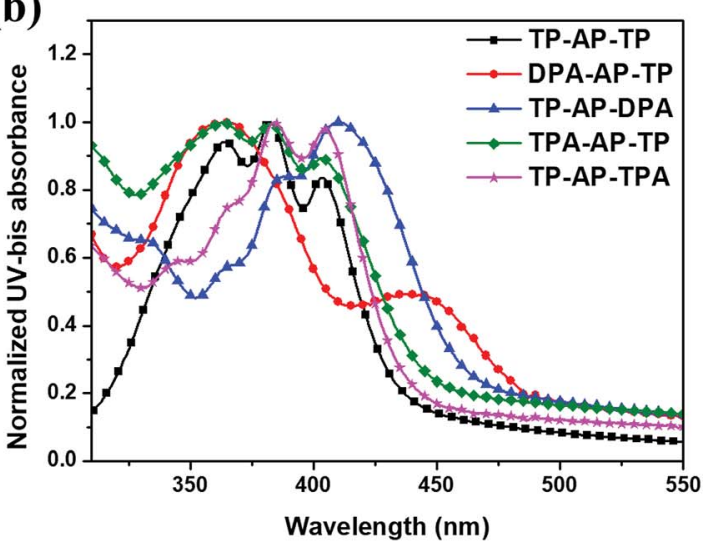

Fig. 1 UV-vis absorption spectra of the synthesized compounds: (a) solution state, (b) film state. 


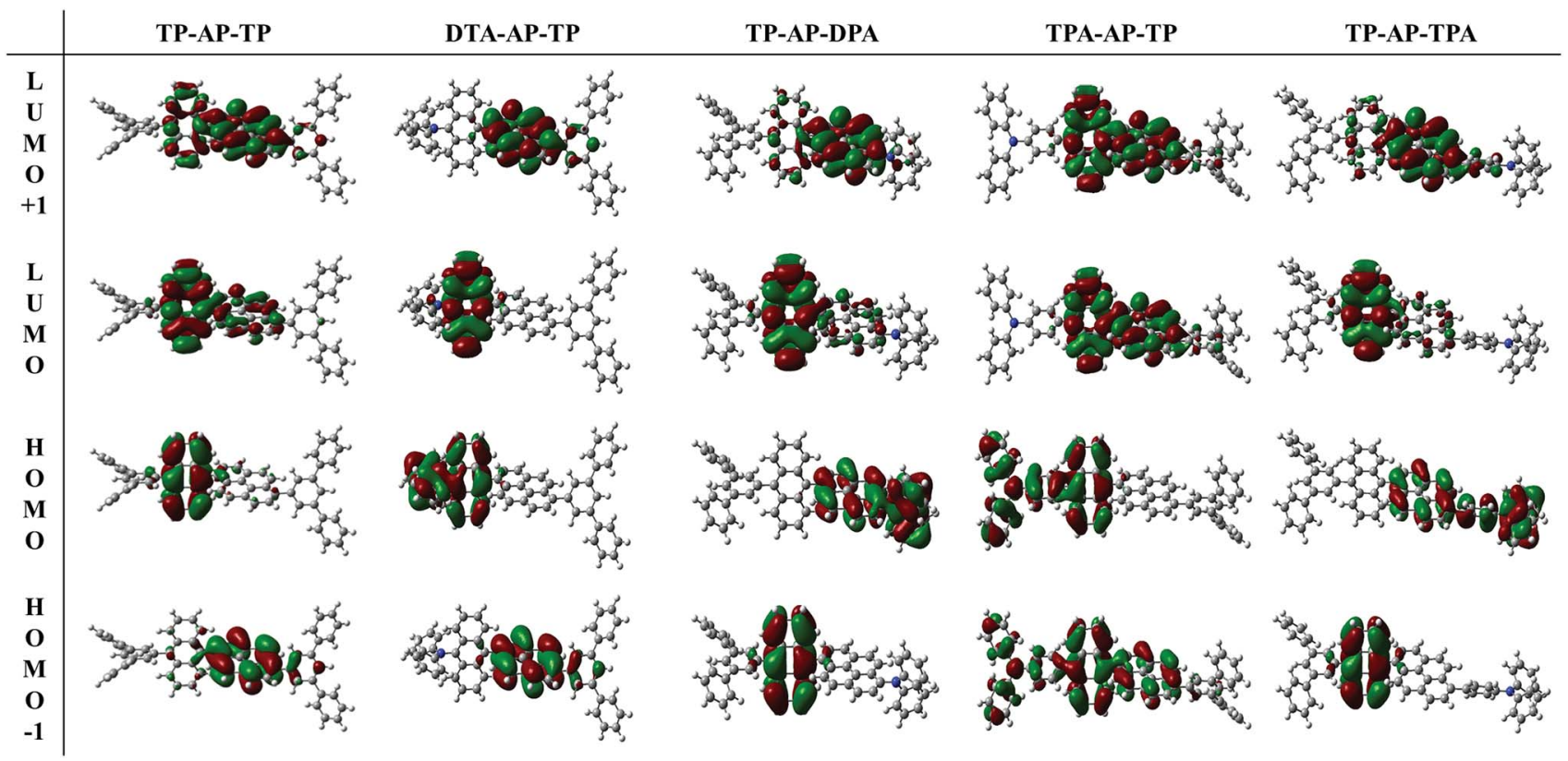

Fig. 2 HOMO-1, HOMO, LUMO and LUMO+1 electronic density distributions of the $\mathrm{S}_{0}$ states of the compounds calculated at the CAM-B3LYP/ $6-31 G(d)$ level.

changes in the intramolecular electron density of the molecules were confirmed by density functional theory (DFT) calculations (CAM-B3LYP/6-31G(d) level). Frontier molecular orbitals of the optimized $\mathrm{S}_{0}$ state molecular structures are shown in Fig. 2. TPAP-TP, with its bulky aromatic side group, showed an absorption wavelength peak of $399 \mathrm{~nm}$ in the solution state (Fig. 1a). On the other hand, DPA-AP-TP (A-1) and TP-AP-DPA (A-2), each containing the electron-donating diphenylamine group, showed absorption wavelength peaks of $428 \mathrm{~nm}$ and $404 \mathrm{~nm}$. TPA-AP-TP (B-1) and TP-AP-TPA (B-2) substituted with a triphenylamine group showed absorption wavelength peaks of $401 \mathrm{~nm}$ and $400 \mathrm{~nm}$. The bathochromic (red) shifts of the absorption wavelength peaks of these four compounds relative to that of TP-AP-TP may have been due to their having increased conjugation lengths in contrast to TP-AP-TP, which only consists of phenyl rings, the type (A) and type (B) molecules substituted with aromatic amine groups were calculated in the HOMO state to display a wide distribution of conjugated electrons, including to the side groups (Fig. 2). The especially large red shift of DPA-AP-TP (A-1) (by $29 \mathrm{~nm}$ compared to that of TPAP-TP) may have been related to its side group substitution being in the anthracene core, whereas in TP-AP-DPA (A-2), with its smaller $(5 \mathrm{~nm})$ red shift, the substitution was done into the pyrene core. The particularly small magnitudes of the red shifts displayed by TPA-AP-TP (B-1) (by only $2 \mathrm{~nm}$ compared to that of TP-AP-TP) and TP-AP-TPA (B-2) (by only $1 \mathrm{~nm}$ ), despite the change in their substitution positions, may have been due to the substituted triphenylamine group of these type (B) molecules, with its additional benzene ring, having a relatively reduced electron-donating ability, compared to the diphenylamine group of the type (A) molecules. The UV-vis absorption peak values in the film state (Fig. 1b) were similar to those in the solution state: in the film state, TP-AP-TP showed an absorption wavelength peak of $403 \mathrm{~nm}$, DPA-AP-TP (A-1) and TP-AP-DPA (A2) showed absorption wavelength peaks of $437 \mathrm{~nm}$ and $410 \mathrm{~nm}$, and TPA-AP-TP (B-1) and TP-AP-TPA (B-2) showed absorption wavelength peak of $405 \mathrm{~nm}$ and $404 \mathrm{~nm}$, which were shorter than those of the type (A) molecules.

HOMO, LUMO and band gap levels of the molecules were measured and calculated using the UV-vis absorption data in the film state and ultraviolet photoelectron spectroscopy (Riken-Keiki, AC-2), as presented in Table 1. The HOMO and LUMO levels of TP-AP-TP were $-6.01 \mathrm{eV}$ and $-3.05 \mathrm{eV}$, yielding a band gap of $2.96 \mathrm{eV}$. Since both type (A) and type (B) molecules have longer conjugation lengths compared to TP-AP-TP, their band gaps were decreased, by $0.26 \mathrm{eV}$ on average: regarding the type (A) molecules, the band gap was $2.51 \mathrm{eV}$ for DPA-AP-TP (A1) (i.e., reduced by $0.45 \mathrm{eV}$ compared to that of TP-AP-TP) and was $2.68 \mathrm{eV}$ for TP-AP-DPA (A-2) (i.e., reduced by $0.28 \mathrm{eV}$ ); regarding the type (B) molecules, the band gap was $2.77 \mathrm{eV}$ for TPA-AP-TP (B-1) (i.e., reduced by $0.19 \mathrm{eV}$ compared to that of TPAP-TP) and $2.83 \mathrm{eV}$ for TP-AP-TPA (B-2) (i.e., reduced by $0.13 \mathrm{eV}$ ). The reduced band gaps of DPA-AP-TP (A-1) and of TPA-AP-TP (B1), whose electron-donating groups were substituted into the anthracene core, compared, respectively, to the band gaps of TP-AP-DPA (A-2) and TP-AP-TPA (B-2), whose side groups were substituted in the pyrene core, occurred despite DPA-AP-TP (A1) and TP-AP-DPA (A-2) having the same substituted aromatic amine side group (i.e., diphenylamine) and despite TPA-AP-TP (B-1) and TP-AP-TPA (B-2) having the same substituted aromatic amine side group (i.e., triphenylamine).

Time dependent (TD)-DFT calculations (TD-CAM-B3LYP/6$31 \mathrm{G}(\mathrm{d})$ ) of the absorption wavelengths and oscillator strengths $(f)$ of the molecules were carried out, and the results of the 
Table 2 Absorption frequencies and oscillator strengths calculated with TD-CAM-B3LYP/6-31G(d) for the synthesized compounds

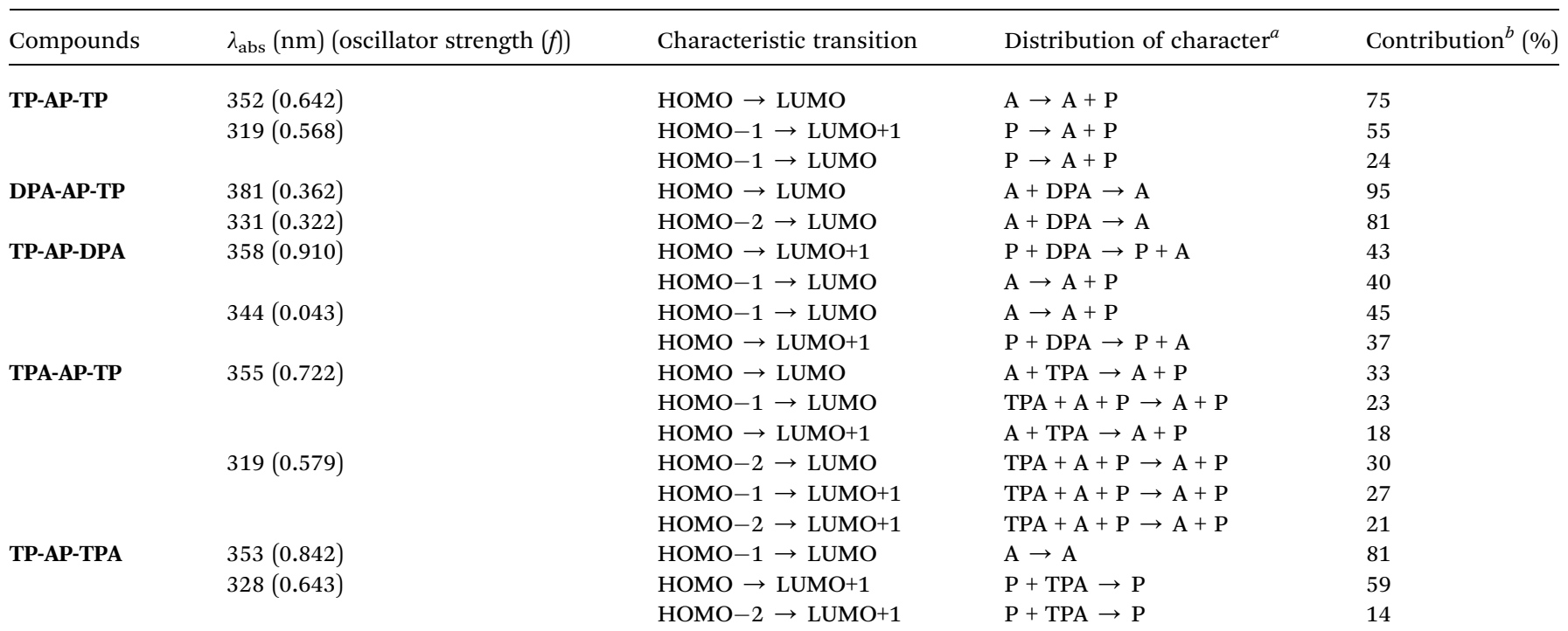

${ }^{a}$ A: anthracene, P: pyrene, DPA: diphenylamine, TPA: triphenylamine. ${ }^{b}$ When the sum of contributions is less than $100 \%$, the remaining contributions include various small portions of transitions. Only the main process was indicated.

calculations are summarized in Table 2. The wavelength shift tendencies of the UV-vis absorption for the compounds obtained by calculations were similar to the experimental results.

From the determined contribution of the electronic transition in the synthesized compound, TP-AP-TP showed an oscillator strength value of 0.642 at a wavelength of $352 \mathrm{~nm}$, and HOMO $\rightarrow$ LUMO was shown to be the main process characterizing the transition here. The electron density distribution (Fig. 2) showed the anthracene core to be the primary source of this process. The oscillator strength value was 0.568 at $319 \mathrm{~nm}$, and HOMO $-1 \rightarrow$ LUMO+1 and HOMO-1 $\rightarrow$ LUMO were found to be the main processes characterizing the electronic transition at this wavelength. The pyrene core was the main source of this process. Comparison of the oscillator strength values at these two wavelengths confirmed the electronic transition in which anthracene participated, rather than that in which the pyrene participated, to be the main factor in the overall process. ${ }^{12}$

Among the type (A) molecules, DPA-AP-TP (A-1), in which the electron-donating diphenylamine group was substituted into the anthracene core, showed oscillator strength values of 0.362 and 0.322 at $381 \mathrm{~nm}$ and $331 \mathrm{~nm}$, respectively. In these two electronic transition processes, the contribution of the anthracene core was found to be the main factor. On the other hand, TP-AP-DPA (A-2), in which the electron-donating group was substituted into the pyrene core, showed an oscillator strength value of 0.910 at $358 \mathrm{~nm}$. Here, the contribution of the electronic transition related to the pyrene core was clearly increased to show the transition process of pyrene.

Similar to type (A) molecules, type (B) molecules also showed an increased electronic transition contribution from each core to which an aromatic amine group was connected. TPA-AP-TP (B-1), in which the triphenylamine group was substituted into the anthracene core, showed oscillator strength values of 0.722 and 0.579 at $355 \mathrm{~nm}$ and $319 \mathrm{~nm}$, respectively, and anthracene acted as the main core. TP-AP-TPA (B-2) showed a high oscillator strength value of 0.842 at $353 \mathrm{~nm}$, with a large contribution of the anthracene core. An oscillator strength value of 0.643 was also shown at $328 \mathrm{~nm}$, and the pyrene core provided the main source of this electronic transition.

While the contribution of the pyrene core to the electronic transition was increased in TP-AP-TPA (B-2) showed electronic transition characteristics similar to those of TP-AP-TP despite substitution of triphenylamine into the pyrene core. This similarity is due to the electron-donating ability of triphenylamine being smaller than that of diphenylamine and hence the triphenylamine group could not change the contribution of pyrene by much. The computational results are consistent with the experimental results, where, among the four type (A) and type (B) materials, TP-AP-TPA (B-2) showed the smallest difference in the band gap compared to that of TP-AP-TP.

The direct attachment of an aromatic amine group to the primary anthracene core results in electron donation to this core. This effect is larger for the connection to an anthracene core than that of the connection to a secondary pyrene core. Thus, as was shown from the results of the optical experiments (such as UV-vis absorption and band gaps), the properties of the DPA-AP-TP (A-1) and TPA-AP-TP (B-1) molecules differed from those of TP-AP-TP to a greater extent than did the properties of the TP-AP-DPA (A-2) and TP-AP-TPA (B-2) molecules.

Photoluminescence (PL) spectra of the synthesized compounds were acquired, and the corresponding data are shown in Fig. 3 and Table 1. TP-AP-TP showed a PL maximum $\left(\mathrm{PL}_{\max }\right)$ value at $446 \mathrm{~nm}$ in the solution state.

Regarding the type (A) molecules, DPA-AP-TP (A-1) showed a $\mathrm{PL}_{\max }$ at $513 \mathrm{~nm}$, i.e., red shifted by $67 \mathrm{~nm}$ compared to that of 

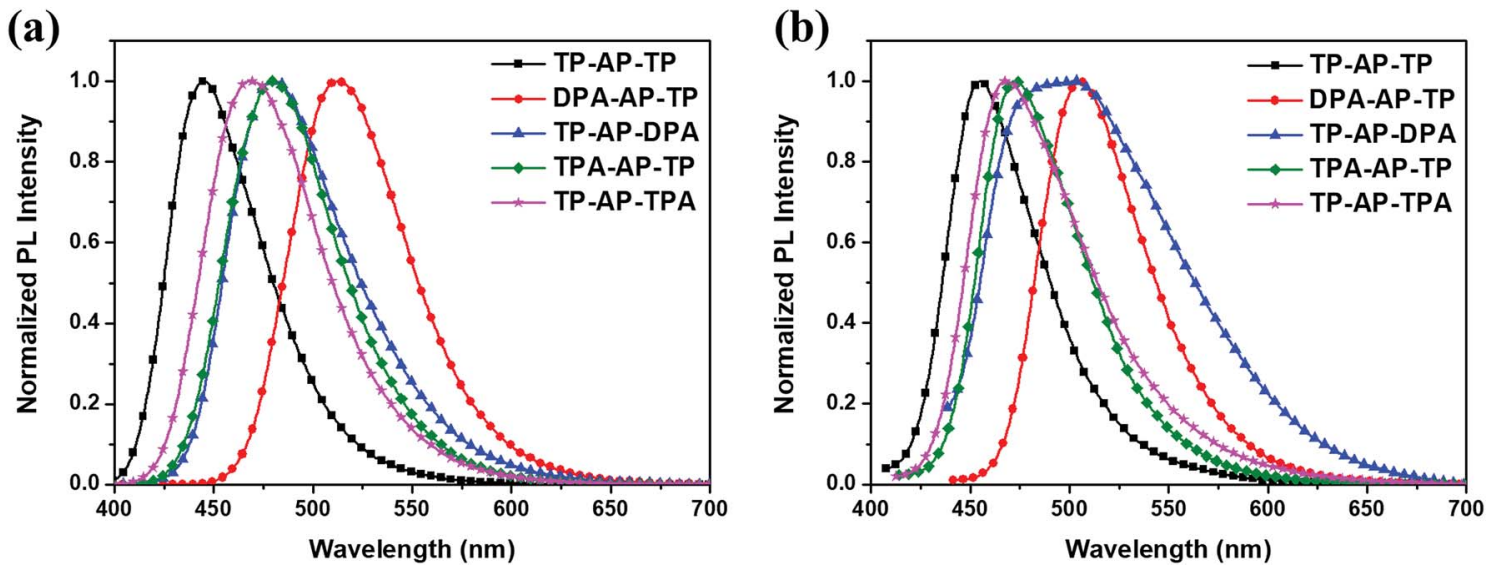

Fig. 3 Normalized PL spectra of the synthesized materials: (a) solution state, (b) film state.

TP-AP-TP, and TP-AP-DPA (A-2) showed a $\mathrm{PL}_{\max }$ at $481 \mathrm{~nm}$, i.e., red shifted by $35 \mathrm{~nm}$. The large red shift of the $\mathrm{PL}_{\max }$ value of DPA-AP-TP (A-1), in which a diphenylamine group was substituted into anthracene, was due to its greatly reduced band gap. ${ }^{10}$ On the other hand, type (B) molecules substituted with the triphenylamine group, which has a relatively small electrondonating effect, showed emissions in the shorter wavelength region compared to type (A) molecules: TPA-AP-TP (B-1) showed a $\mathrm{PL}_{\max }$ at $479 \mathrm{~nm}$, i.e., red shifted by $33 \mathrm{~nm}$ compared to that of
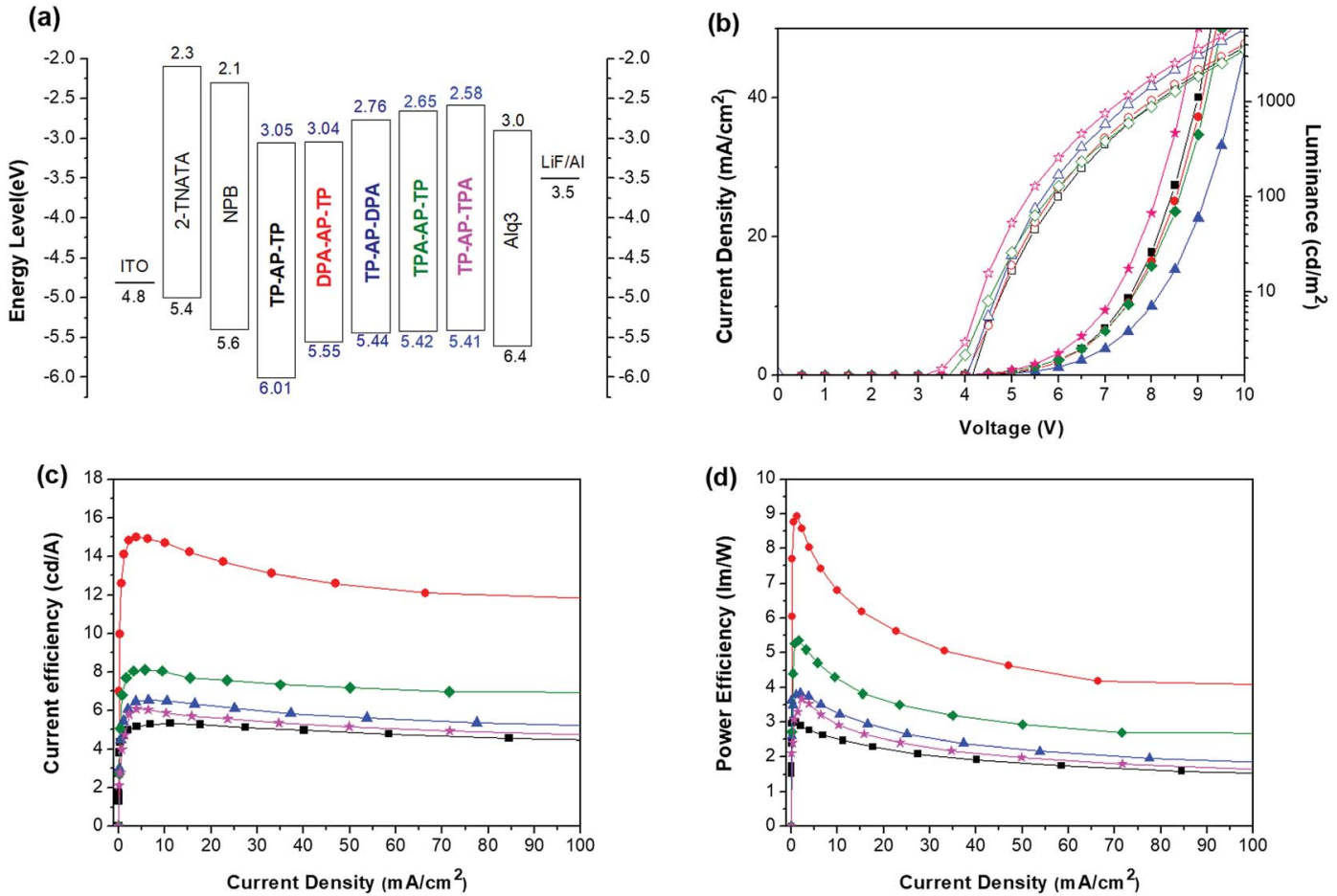

$--\square-$ TP-AP-TP $--0-$ DPA-AP-TP $-\triangle-\triangle-$ TP-AP-DPA

Fig. 4 EL characteristics of devices using the synthesized compounds as EMLs: (a) energy levels of the organic materials, (b) $I-V-L$ curves, (c) current efficiency (CE) versus current density, and (d) power efficiency (PE) versus current density.
TP-AP-TP; and TP-AP-TPA (B-2) showed a $\mathrm{PL}_{\max }$ at $467 \mathrm{~nm}$, i.e., red shifted by $21 \mathrm{~nm}$.

The FWHM values of the PL spectra were also analyzed. In the solution state, TP-AP-TP showed a narrow value of $56 \mathrm{~nm}$, whereas the type (A) and type (B) molecules, in which an aromatic amine group was substituted into the core, showed FWHM values increased to 63-67 $\mathrm{nm}$. This increase can be interpreted as a diversification of the electronic transition channels due to a broadened distribution of intramolecular electron density following substitution of an electron donating 
Table 3 Electroluminescence efficiency of the synthesized compounds at $10 \mathrm{~mA} \mathrm{~cm}{ }^{-2}$ : ITO/2-TNATA (60 nm)/NPB (15 nm)/emitting layer $(35 \mathrm{~nm}) /$ Alq3 $(20 \mathrm{~nm}) / \mathrm{LiF}(1 \mathrm{~nm}) / \mathrm{Al}$

\begin{tabular}{llcllll}
\hline Compound & Volt $(\mathrm{v})$ & CE $\left(\mathrm{cd} \mathrm{A}^{-1}\right)$ & PE $\left(\mathrm{lm} \mathrm{W}^{-1}\right)$ & CIE $(x, y)$ & EL $(\mathrm{nm})$ & EL FWHM $(\mathrm{nm})$ \\
\hline TP-AP-TP & 7.19 & 5.34 & 2.58 & $(0.15,0.13)$ & 456 & 55 \\
DPA-AP-TP & 7.49 & 13.05 & 6.83 & $(0.19,0.56)$ & 501 & 57 \\
TP-AP-DPA & 6.93 & 6.50 & 3.27 & $(0.24,0.51)$ & 504 & 69 \\
TPA-AP-TP & 6.56 & 8.05 & 4.25 & $(0.14,0.24)$ & 473 & 53 \\
TP-AP-TPA & 6.96 & 5.89 & 2.96 & & & 572 \\
\end{tabular}

side group into the core. ${ }^{14}$ Increases in the FWHM values of the type (A) and type (B) molecules were also shown in film state. An especially high FWHM value of $106 \mathrm{~nm}$, with two $\mathrm{PL}_{\max }$ values, at $487 \mathrm{~nm}$ and $502 \mathrm{~nm}$, were observed for the film state of the TP-AP-DPA (A-2) molecule, in which diphenylamine was substituted into pyrene. This feature was probably caused by a solid-state-specific intermolecular excimer. To clarify whether the emissions at, say, $502 \mathrm{~nm}$ is excimer peak corresponding to PL emission from the molecule, excitation spectra were measured along with the UV-vis absorption spectrum (see Fig. S2†). The UV-vis absorption spectrum matched well with the excitation spectra. The excitation spectra monitored at $487 \mathrm{~nm}$ and $502 \mathrm{~nm}$ were observed to be very similar, indicating that they arose from the same excitation pathway. This finding is consistent with the value at $502 \mathrm{~nm}$ resulting from an excimer emission. Also, as shown in Fig. S3, $\uparrow$ TP-AP-DPA (A-2) displays a dihedral angle between its pyrene and side group of only $68^{\circ}$ and has a relatively small side group, and would hence appear to have a reduced ability to prevent intermolecular packing and excimer formation compared to DPA-AP-TP (A-1), which, while also having a relatively small side group, displays an increased dihedral angle between its anthracene and side group of $75^{\circ}$. Therefore, in addition to the size of the side group, the dihedral angle by itself may be a factor determining excimer formation. In case of TP-AP-TPA (B-2), it did not show excimer emission because of a relatively large side group.

\subsection{Electroluminescence properties}

Five different non-doped OLED devices (device configuration: ITO $/ 4,4^{\prime}, 4^{\prime \prime}$-tris[2-naphthyl(phenyl)amino]triphenylamine [2TNATA] $60 \mathrm{~nm} / N, \mathrm{~N}^{\prime}$-bis(naphthalen-1-yl)- $N, N^{\prime}$-bis(phenyl) benzidine [NPB] $15 \mathrm{~nm} /$ synthesized emitting materials $35 \mathrm{~nm} /$ tris(8-hydroxyquinolinato)aluminum [Alq3] $20 \mathrm{~nm} / \mathrm{LiF} 1 \mathrm{~nm} / \mathrm{Al}$ $200 \mathrm{~nm}$ ) were prepared using the five synthesized molecules as the respective emitting layers (EMLs), and the EL performances of the devices were measured. 2-TNATA was used as the hole-injection layer, NPB as the hole-transporting layer, and Alq3 as the electron-transporting layer. Emitting materials were applied as a single layer with a non-doped structure.

For each of the five devices, the shape and maximum wavelength of the EL spectrum remained unchanged as the luminance was increased from $500 \mathrm{~cd} \mathrm{~m}^{-2}$ to $3000 \mathrm{~cd} \mathrm{~m}^{-2}$ (see Fig. S4 $\dagger$ ). All of the devices were confirmed to properly form excitons in the EML and operate stably. The OLED device properties are summarized in Fig. 4 and Table 3.
As was observed for its emission properties, TP-AP-TP of the reference material, which only consists of phenyl rings, yielded an EL maximum $\left(\mathrm{EL}_{\max }\right)$ wavelength of $456 \mathrm{~nm}$ and blue color coordinates with Commission International de L'Eclairge (CIE) coordinates $(x, y)$ of $(0.15,0.13)$. Also, it showed a CE of $5.34 \mathrm{~cd} \mathrm{~A}^{-1}$ and power efficiency (PE) of $2.58 \mathrm{~lm} \mathrm{~W}^{-1}$ under a current density of $10 \mathrm{~mA} \mathrm{~cm}{ }^{-2}$. Compared to TP-AP-TP, devices that applied type (A) and type (B) molecules as the EML showed shifting of the emission wavelength to longer wavelengths, as found for PL, but both CE and PE were increased (see Fig. 5). These shifts were caused by the electron-donating aromatic amine moieties. $^{\mathbf{1 0}}$

DPA-AP-TP (A-1) yielded the highest device efficiencies of $13.05 \mathrm{~cd} \mathrm{~A}^{-1}$ and $6.83 \mathrm{~lm} \mathrm{~W}^{-1}$, but an emission with CIE $x, y(0.19$, 0.56) due to the squeezed band gap. TP-AP-DPA (A-2) showed EL efficiencies of $6.50 \mathrm{~cd} \mathrm{~A}^{-1}$ and $3.27 \mathrm{~lm} \mathrm{~W}^{-1}$ and a CIE $x, y(0.24$, 0.51). Also, EL efficiencies of TPA-AP-TP (B-1) were $8.05 \mathrm{~cd} \mathrm{~A}^{-1}$ and $4.25 \mathrm{~lm} \mathrm{~W}^{-1}$, and EL efficiencies of TP-AP-TPA (B-2) were $5.89 \mathrm{~cd} \mathrm{~A}^{-1}$ and $2.96 \mathrm{~lm} \mathrm{~W}^{-1}$. They yielded color coordinate values of CIEx,y $(0.14,0.24)$ and CIEx $y(0.16,0.29)$, respectively. MADN and DPVBi, which are well-known blue reference emitters, showed CE values of 2.86 and $3.92 \mathrm{~cd} \mathrm{~A}^{-1}$, PE values of 1.48 and $1.61 \mathrm{~lm} \mathrm{~W}^{-1}$, and EL maximum values of 454 and $465 \mathrm{~nm}$, respectively [see Table S1†]. Comparing to the data of the reference emitters, TPA-AP-TP had over two times higher CE and PE values than those of MADN and DPVBi although EL maximum value was red-shifted 7-18 nm compared to MADN and DPVBi.

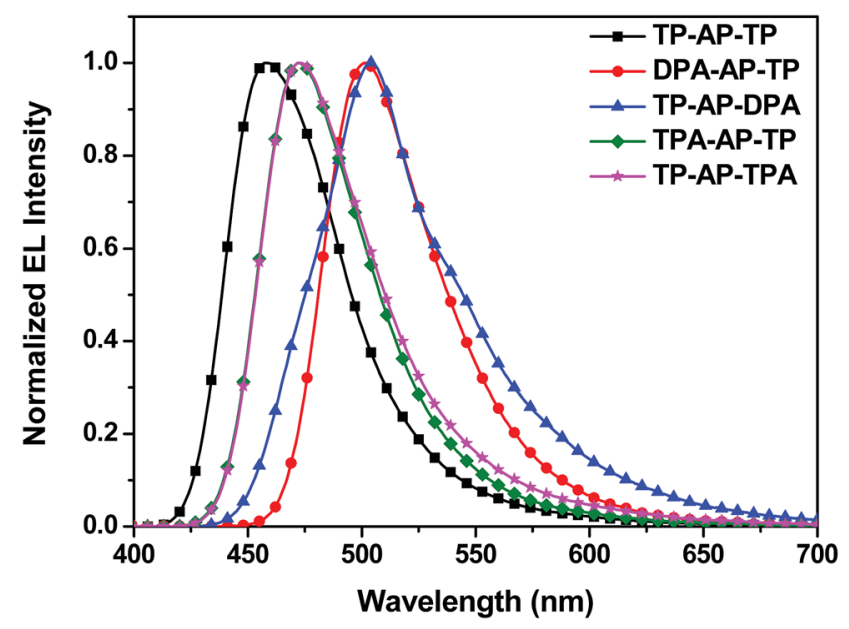

Fig. 5 EL spectra of devices using the synthesized compounds. 
Comparing CE and CIEx,y values of type (A) and type (B) molecules, type (A) molecules substituted with the diphenylamine group showed higher $\mathrm{CE}$ values compared to type (B) molecules. However, the EL emission was shifted more to longer wavelengths, and CIEx,y values were also increased. On the other hand, type (B) molecules, with their triphenylamine group and its reduced electron-donating ability, displayed a relatively small shift of the EL wavelength and were found to have optimized CIEx,y values for the sky-blue color. The TPA-APTP (B-1) molecule, with its bulky triphenylamine side group substituted into the primary anthracene core, yielded especially excellent EL efficiencies of $8.05 \mathrm{~cd} \mathrm{~A}^{-1}$ and $4.25 \mathrm{~lm} \mathrm{~W}^{-1}$ as well as a narrow FWHM value of $53 \mathrm{~nm}$. This study verified that in heterocore molecules such as the AP core, one of the two cores functions as the primary core and contributes more to the electronic transition than does the other, i.e., secondary, coreand that the largest changes to the optical and electronic properties of the final heterocore derivatives can be achieved by simply substituting an electron-donating side group into a position on the primary core. Such a methodology could be applied to develop excellent blue light-emitting materials applicable to OLED lighting.

\section{Conclusions}

This study examined hetero dual-core chromophores in which anthracene and pyrene are connected. The hetero dual-core chromophores included anthracene to be the primary core and pyrene to be the secondary core. We specifically investigated the effects of changing the side group on the performance properties of the final compounds. A nitrogen atom was introduced in order to increase electron donation to the dual core and hence increased device efficiency, and a bulky side group of triphenylamine was introduced to suppress intermolecular interactions. Especially, electron-donating side groups were substituted at different positions of TP-AP-TP, a molecule with a hetero dual-core structure, in order to determine whether one of its two cores, and if so which one, contributes more to changes in the optical and electronic properties of the resulting material.

The electron density distribution within the molecule and the part of the molecule contributing to the electronic transition were confirmed to be affected by the substitution of the electronically optimized side group into the core. The TPA-AP-TP molecule, whose side group not only displays optimum electron donation to what was determined to be the main core, but also has a proper size, yielded a non-doped OLED device with high efficiency values of $8.05 \mathrm{~cd} \mathrm{~A}^{-1}$ and $4.25 \mathrm{~lm} \mathrm{~W}^{-1}$ as well as a narrow FWHM value of $53 \mathrm{~nm}$. Comparing to the data of the reference emitters, TPA-AP-TP had two times higher CE and PE values than those of MADN and DPVBi.

This study verified that the largest changes to the optical and electronic properties of the final heterocore derivatives can be achieved by substituting an electron-donating side group into a position on the primary core.

This systematic methodology can be applied to develop new various other OLED emitters of blue light for OLED lighting based on many multi-core chromophores by introducing various electron-donating moieties to the main core.

\section{Experimental section}

\subsection{General information}

The requisite reagents were purchased from Sigma-Aldrich or TCI and were used without further purification, unless otherwise noted. The ${ }^{1} \mathrm{H}$-NMR spectra were recorded on Bruker Avance 300 spectrometers. The $\mathrm{FAB}^{+}$-mass and $\mathrm{EI}^{+}$-spectra were recorded on a JEOL, JMS-AX505WA, HP5890 series II. The optical absorption spectra were obtained by using a Lambda 1050 UV/vis/NIR spectrometer (PerkinElmer). A PerkinElmer luminescence spectrometer LS50 (Xenon flash tube) was used to perform photoluminescence spectroscopy. The glass-transition temperatures $\left(T_{\mathrm{g}}\right)$ of the compounds were determined with differential scanning calorimetry (DSC) under a nitrogen atmosphere by using a DSC4000 (PerkinElmer). Samples were heated to $500{ }^{\circ} \mathrm{C}$ at a rate of $10{ }^{\circ} \mathrm{C} \mathrm{min}{ }^{-1}$ and cooled at $10{ }^{\circ} \mathrm{C} \min ^{-1}$ then heated again under the same heating conditions as used in the initial heating process. Degradation temperatures $\left(T_{\mathrm{d}}\right)$ were determined with thermo gravimetric analysis (TGA) by using a TGA4000 (PerkinElmer). Samples were heated to $700{ }^{\circ} \mathrm{C}$ at a rate of $10{ }^{\circ} \mathrm{C} \mathrm{min}^{-1}$. The HOMO energy levels were determined with ultraviolet photoelectron yield spectroscopy (Riken Keiki AC-2). The LUMO energy levels were derived from the HOMO energy levels and the band gaps. All DFT and TD-DFT calculations were performed using the Gaussian09 (ref. 15) program. In each of the EL devices, $4,4^{\prime}, 4^{\prime \prime}$ tris[2-naphthyl(phenyl)amino] triphenylamine (2-TNATA) was used as the hole-injection layer, $N, N^{\prime}$-bis(naphthalen-1-yl)$N, 5 N^{\prime}$-bis(phenyl)benzidine (NPB) was used for the hole transporting layer, one of the synthetic materials TP-AP-TP, DPA-APTP, TP-AP-DPA, TPA-AP-TP and TP-AP-TPA were used as the emitting layer (EML), emitting materials were applied as a single layer with a non-doped structure. Tris(8hydroxyquinolinato)aluminum (Alq3) was used for the electron transporting (ETL), lithium fluoride (LiF) was used for the electron injection layer (EIL), and ITO was used as the anode and aluminum (Al) as the cathode. All organic layers were deposited under $10^{-6}$ Torr, with a rate of deposition of $1.0 \AA^{-1}$ to create an emitting area of $4 \mathrm{~mm}^{2}$. The $\mathrm{LiF}$ and aluminum layers were continuously deposited under the same vacuum conditions. The luminance efficiency data for the fabricated EL devices were obtained by using a Keithley 2400 electrometer. Light intensities were obtained with a Minolta CS-1000A. The operational stabilities of the devices were measured under encapsulation in a glove box.

4.1.1 Synthesis of compound [1]. 9-Bromoanthracene (Aldrich, 94\%) (10 g, $38.9 \mathrm{mmol}$ ) was dissolved in $500 \mathrm{~mL}$ of anhydrous THF solution and stirred at $-78{ }^{\circ} \mathrm{C}$. Then, $n$-butyllithium solution (Aldrich, 1.6 $\mathrm{M}$ in hexane) $(29.3 \mathrm{~mL}$, $46.7 \mathrm{mmol}$ ) was added. Triethyl borate (Aldrich, 99\%) $(9.3 \mathrm{~mL}$, $54.5 \mathrm{mmol}$ ) was added to the reaction after $30 \mathrm{~min}$. After the reaction was finished, the solution was acidified with $2 \mathrm{~N} \mathrm{HCl}$ solution and extracted with ethyl acetate and water. The organic layer was dried with anhydrous $\mathrm{MgSO}_{4}$ and filtered. The 
solution was evaporated. The residue was redissolved in hexane and added to ethyl acetate $(50 \mathrm{~mL})$. The precipitate was filtered and washed with hexane to obtain a beige compound $(7.3 \mathrm{~g}$, 85\%). ${ }^{1} \mathrm{H}-\mathrm{NMR}\left(300 \mathrm{MHz}, \mathrm{CDCl}_{3}, \mathrm{~d}\right): 8.46$ (s, 1H), 8.12 (d, 2H), $8.01(\mathrm{~d}, 2 \mathrm{H}), 7.48(\mathrm{~m}, 4 \mathrm{H}), 5.07$ (s, 2H).

4.1.2 Synthesis of compound [2]. Bromine (TCI, 98\%) $(10 \mathrm{~mL}, 194.7 \mathrm{mmol})$ in $\mathrm{CHCl}_{3}(500 \mathrm{~mL})$ was added to a solution of pyrene (TCI, 97\%) (20 g, $98.9 \mathrm{mmol})$ in $\mathrm{CHCl}_{3}(500 \mathrm{~mL})$ over $5 \mathrm{~h}$ while stirring. The precipitate was collected after $12 \mathrm{~h}$ and resolved by fractional crystallization from xylene $(11.8 \mathrm{~g}, 33 \%)$. ${ }^{1} \mathrm{H}-\mathrm{NMR}\left(300 \mathrm{MHz}, \mathrm{CDCl}_{3}, \mathrm{~d}\right): 8.46$ (d, 2H), 8.27 (d, 2H), 8.12 (d, 2H), 8.06 (d, 2H).

4.1.3 Synthesis of compound [3]. 4-Bromotriphenylamine (Aldrich, 97\%) (5 g, $15.4 \mathrm{mmol}$ ) was added in $200 \mathrm{~mL}$ of anhydrous THF solution and stirred at $-78{ }^{\circ} \mathrm{C}$, then $n$-butyllithium solution (Aldrich, 2.0 M in cyclohexane) $(7.7 \mathrm{~mL})$ was added. Next, triethyl borate (Aldrich, 99\%) (3.93 mL) was added to the reaction mixture after $30 \mathrm{~min}$. After the reaction had finished, $\mathrm{HCl} 35 \mathrm{wt} \%$ solution was added to the reaction mixture after $3 \mathrm{~h}$. The reaction mixture was extracted with diethyl ether and water. The organic layer was dried with anhydrous $\mathrm{MgSO}_{4}$ and filtered. The mixture was evaporated. The product was recrystallized from dichloromethane $\left(\mathrm{CH}_{2} \mathrm{Cl}_{2}\right)$ and hexane. (yield 65\%). ${ }^{1} \mathrm{H}-\mathrm{NMR}\left(300 \mathrm{MHz}, \mathrm{CDCl}_{3}, 25{ }^{\circ} \mathrm{C}, \mathrm{TMS}\right): \delta=8.77(\mathrm{~m}, 2 \mathrm{H})$, $8.63(\mathrm{~d}, 1 \mathrm{H}), 7.62(\mathrm{~m}, 3 \mathrm{H}), 7.35(\mathrm{t}, 2 \mathrm{H}), 7.22 \mathrm{ppm}(\mathrm{m}, 4 \mathrm{H})$.

4.1.4 Synthesis of compound [4]. 1,3,5-Tribromobenzene (Aldrich, 98\%) (20 g, $63 \mathrm{mmol}), \mathrm{Pd}\left(\mathrm{PPh}_{3}\right)_{4}$ (Aldrich, 99\%) (4.36 g, $3.7 \mathrm{mmol}$ ) were added to $500 \mathrm{~mL}$ of dry THF solution. Then, phenylboronic acid (Aldrich, 95\%) (17 g, $140 \mathrm{mmol}$ ) and $2 \mathrm{M} \mathrm{K}_{2} \mathrm{CO}_{3}$ solution ( $50 \mathrm{~mL}$ ), which was dissolved in $\mathrm{H}_{2} \mathrm{O}$, was added to the reaction mixture. The reaction mixture was heated to $65{ }^{\circ} \mathrm{C}$ for $5 \mathrm{~h}$ under nitrogen. After the reaction was finished, diethyl ether and water were extracted. The organic layer was dried with anhydrous $\mathrm{MgSO}_{4}$ and filtered. The solvent was evaporated. The product was isolated by silica gel column chromatography using $\mathrm{CHCl}_{3}$ : hexane $(1: 15)$ eluent to afford a white solid. (Yield 61\%) ${ }^{1} \mathrm{H}$ NMR $\left(300 \mathrm{MHz}, \mathrm{CDCl}_{3}, 25{ }^{\circ} \mathrm{C}\right.$, TMS): $\delta=7.70(\mathrm{~s}, 3 \mathrm{H}), 7.60(\mathrm{~d}, 4 \mathrm{H}), 7.44(\mathrm{t}, 4 \mathrm{H}), 7.36 \mathrm{ppm}(\mathrm{t}, 2 \mathrm{H})$.

4.1.5 Synthesis of compound [5]. Compound 1 (6.0 g, 19.4 $\mathrm{mmol}$ ) was dissolved in $400 \mathrm{~mL}$ of anhydrous THF solution and stirred at $-78{ }^{\circ} \mathrm{C}$. Then, the $n$-butyllithium solution (Aldrich, $2.0 \mathrm{M}$ in cyclohexane) $(10 \mathrm{~mL})$ was added. Then, isopropoxy4,4,5,5-tetramethyl-1,3,2-dioxaborolane (Aldrich, 98\%) (6 mL) was added to the reaction mixture. After the reaction was finished, diethyl ether and water were extracted. The organic layer was dried by evaporator. The product was recrystallized from chloroform and methanol. (Yield 86.9\%) ${ }^{1} \mathrm{H}$ NMR $(300$ $\left.\mathrm{MHz}, \mathrm{CDCl}_{3}, 25{ }^{\circ} \mathrm{C}, \mathrm{TMS}\right): \delta=8.03(\mathrm{~s}, 2 \mathrm{H}), 7.90(\mathrm{~s}, 1 \mathrm{H}), 7.69(\mathrm{~d}$, $4 \mathrm{H}), 7.44(\mathrm{t}, 4 \mathrm{H}), 7.35(\mathrm{t}, 2 \mathrm{H}), 1.37 \mathrm{ppm}(\mathrm{s}, 12 \mathrm{H})$.

4.1.6 Synthesis of compound [6]. Compound 2 (9.7 g, $27.0 \mathrm{mmol}$ ) and $\mathrm{Pd}\left(\mathrm{PPh}_{3}\right)_{4}$ (Aldrich, 99\%) (0.62 g, $\left.0.54 \mathrm{mmol}\right)$ were added to $150 \mathrm{~mL}$ of anhydrous toluene solution. Then, compound 1 ( $4 \mathrm{~g}, 18.0 \mathrm{mmol})$, anhydrous ethanol $(8 \mathrm{~mL})$, and $2 \mathrm{M} \mathrm{K}_{2} \mathrm{CO}_{3}$ solution ( $15 \mathrm{~mL}$ ) dissolved in $\mathrm{H}_{2} \mathrm{O}$ were added to the reaction mixture. The mixture was heated to $65^{\circ} \mathrm{C}$ for $5 \mathrm{~h}$ under nitrogen. After the reaction was finished, the reaction mixture was extracted with toluene and water. The organic layer was dried with anhydrous $\mathrm{MgSO}_{4}$ and filtered. The solution was evaporated. The product was isolated with silica gel column chromatography by using $\mathrm{CH}_{2} \mathrm{Cl}_{2}: n$-hexane $(1: 7)$ as the eluent to afford a beige solid. (3.9 g, 32\%). ${ }^{1} \mathrm{H}-\mathrm{NMR}\left(300 \mathrm{MHz}, \mathrm{CDCl}_{3}\right.$, d): $8.65(\mathrm{~s}, 1 \mathrm{H}), 8.55(\mathrm{~d}, 1 \mathrm{H}), 8.41(\mathrm{~d}, 1 \mathrm{H}), 8.32(\mathrm{~d}, 1 \mathrm{H}), 8.24(\mathrm{~d}$, $1 \mathrm{H}), 8.16(\mathrm{~d}, 2 \mathrm{H}), 8.06(\mathrm{~d}, 1 \mathrm{H}), 7.93(\mathrm{~d}, 1 \mathrm{H}) 7.72(\mathrm{~d}, 1 \mathrm{H}), 7.47(\mathrm{t}$, $2 \mathrm{H}), 7.33(\mathrm{~d}, 1 \mathrm{H}), 7.30(\mathrm{~d}, 2 \mathrm{H}), 7.22(\mathrm{t}, 2 \mathrm{H})$.

4.1.7 Synthesis of compound [7]. Compound $6(1.0 \mathrm{~g}$, $2.19 \mathrm{mmol}$ ) and $N$-bromosuccinimide (Aldrich, 99\%) (0.43 g, $2.42 \mathrm{mmol}$ ) were added to $30 \mathrm{~mL}$ of $\mathrm{CHCl}_{3}$, and acetic acid $(5 \mathrm{~mL})$ was added to the reaction mixture. The mixture was refluxed for $2 \mathrm{~h}$. After the reaction was finished, the reaction mixture was extracted with $\mathrm{CHCl}_{3}$ and water. The organic layer was dried with anhydrous $\mathrm{MgSO}_{4}$ and filtered. The solution was evaporated. The residue was re-dissolved in ethanol and added to $\mathrm{CHCl}_{3}(50 \mathrm{~mL})$. The precipitate was filtered and washed with ethanol to obtain a yellow compound $(1.1 \mathrm{~g}, 96 \%) .{ }^{1} \mathrm{H}-\mathrm{NMR}(300$ $\left.\mathrm{MHz}, \mathrm{CDCl}_{3}, \mathrm{~d}\right): 8.69$ (d, 2H), 8.57 (d, 1H), 5.42 (d, 1H), 8.33 (d, $1 \mathrm{H}), 8.25(\mathrm{~d}, 1 \mathrm{H}), 8.03(\mathrm{~d}, 1 \mathrm{H}), 7.95(\mathrm{~d}, 1 \mathrm{H}), 7.74(\mathrm{~d}, 1 \mathrm{H}), 7.60(\mathrm{~m}$, $2 \mathrm{H}), 7.30(\mathrm{~d}, 2 \mathrm{H}), 7.29(\mathrm{~d}, 1 \mathrm{H}), 7.26(\mathrm{~m}, 2 \mathrm{H})$.

4.1.8 Synthesis of TP-AP-TP [8]. Compound 5 (0.8 g, $4.8 \mathrm{mmol}$ ), compound 7 (1.0 g, $1.9 \mathrm{mmol}), \mathrm{Pd}(\mathrm{OAc})_{2}$ (Aldrich, 98\%) (0.04 g, $0.19 \mathrm{mmol})$, and (cyclohexyl) ${ }_{3} \mathrm{P}$ (Aldrich) (0.13 g, $0.46 \mathrm{mmol})$ were added to anhydrous THF $(100 \mathrm{~mL})$ solution. Then, tetraethylammonium hydroxide $(20 \mathrm{wt} \%)(10 \mathrm{~mL})$ was added to the reaction mixture. The mixture was heated to $85{ }^{\circ} \mathrm{C}$ for $2 \mathrm{~h}$ under nitrogen. After the reaction was finished, the reaction mixture was extracted with $\mathrm{CHCl}_{3}$ and water. The organic layer was dried with anhydrous $\mathrm{MgSO}_{4}$ and filtered. The solution was evaporated. The residue was re-dissolved in $\mathrm{CHCl}_{3}$ and added to ethanol. The precipitate was filtered and washed with ethanol. The yellowish powder was purified by using column chromatography with $\mathrm{CH}_{2} \mathrm{Cl}_{2}: n$-hexane $(1: 7)$ as the eluent to afford a beige solid (TP-AP-TP) $(1.0 \mathrm{~g}, 63 \%) .{ }^{1} \mathrm{H}-\mathrm{NMR}$ (500 MHz, $\left.\mathrm{CDCl}_{3}, \mathrm{~d}\right): 8.43$ (d, 1H), 8.40 (d, 1H), 8.22 (d, 1H), 8.21 (d, 1H), 8.11 (d, 2H), 8.08 (s, 1H), $7.97(\mathrm{~m}, 3 \mathrm{H}), 7.89(\mathrm{~m}, 4 \mathrm{H}), 7.79$ (m, 9H), $7.50(\mathrm{~m}, 9 \mathrm{H}), 7.40(\mathrm{~m}, 8 \mathrm{H}), 7.21(\mathrm{t}, 2 \mathrm{H}) ;{ }^{13} \mathrm{C}-\mathrm{NMR}(500$ $\mathrm{MHz}, \mathrm{CDCl}_{3}$, d): 142.31, 141.99, 141.92, 141.04, 140.87, 140.12, $137.88,137.39$, 135.66, 134.40, 131.28, 131.02, 130.98, 130.72, $130.07,129.71,129.19,129.00,128.94,128.92,128.44,127.91$, $127.84,127.82,127.64,127.42,127.38,127.22,127.19,125.94$, 125.61, 125.39, 125.35, 125.20, 125.14, 125.10, 124.94, 124.74; HRMS (EI, $m / z$ ): $[\mathrm{M}]^{+}$calcd for $\mathrm{C}_{56} \mathrm{H}_{42}, 834.3287$; found, 834.3289. Anal. calcd for $\mathrm{C}_{56} \mathrm{H}_{42}$ : C 94.93, H5.07; found: C 94.23, H 5.06\%.

4.1.9 Synthesis of compound [9]. Compound 6 (2 g, $4.3 \mathrm{mmol}), \mathrm{Pd}\left(\mathrm{PPh}_{3}\right)_{4}$ (Aldrich, 99\%) (0.15 g, $0.13 \mathrm{mmol}$ ) were added to $50 \mathrm{~mL}$ of anhydrous THF solution. Then, compound 5 $(2.3 \mathrm{~g}, 6.4 \mathrm{mmol})$ and $2 \mathrm{M} \mathrm{K}_{2} \mathrm{CO}_{3}$ solution $(10 \mathrm{~mL})$, which was dissolved in $\mathrm{H}_{2} \mathrm{O}$, was added to the reaction mixture. The reaction mixture was heated to $85{ }^{\circ} \mathrm{C}$ for $3 \mathrm{~h}$ under nitrogen. After the reaction was finished, diethyl ether and water were extracted. The organic layer was dried with anhydrous $\mathrm{MgSO}_{4}$ and filtered. The solvent was evaporated. The product was isolated by silica gel column chromatography using $\mathrm{CHCl}_{3}$ : hexane (1:5) eluent to afford a white solid. (Yield 61\%) ${ }^{1} \mathrm{H}$ NMR (300 MHz, DMSO, $25{ }^{\circ} \mathrm{C}$, TMS): $\delta=8.88$ (s, $\left.1 \mathrm{H}\right), 8.56$ (d, 
$1 \mathrm{H}), 8.38(\mathrm{t}, 3 \mathrm{H}), 8.28(\mathrm{t}, 3 \mathrm{H}), 8.11(\mathrm{~m}, 2 \mathrm{H}), 8.08(\mathrm{~d}, 1 \mathrm{H}), 7.95(\mathrm{~m}$, $6 \mathrm{H}), 7.56(\mathrm{t}, 6 \mathrm{H}), 7.46(\mathrm{t}, 2 \mathrm{H}), 7.34(\mathrm{t}, 2 \mathrm{H}), 7.23(\mathrm{~m}, 3 \mathrm{H})$.

4.1.10 Synthesis of compound [10]. Compound $9(1.0 \mathrm{~g}$, $1.6 \mathrm{mmol}$ ) and $\mathrm{N}$-bromosuccinimide (Aldrich, 99\%) (0.32 g, $1.8 \mathrm{mmol}$ ) were added to $30 \mathrm{~mL}$ of $\mathrm{CHCl}_{3}$, and acetic acid $(3 \mathrm{~mL})$ was added to the reaction mixture. The mixture was refluxed for $3 \mathrm{~h}$. After the reaction was finished, the reaction mixture was extracted with $\mathrm{CHCl}_{3}$ and water. The organic layer was dried with anhydrous $\mathrm{MgSO}_{4}$ and filtered. The solution was evaporated. The residue was re-dissolved in ethanol and added to $\mathrm{CHCl}_{3}(50 \mathrm{~mL})$. The precipitate was filtered and washed with ethanol to obtain a yellow compound (yield 76\%). ${ }^{1} \mathrm{H}-\mathrm{NMR}$ (300 MHz, [D $\mathrm{D}_{6}$ ] DMSO $\left.25{ }^{\circ} \mathrm{C}, \mathrm{TMS}\right): 8.65$ (d, 2H), 8.55 (d, 1H), $8.37(\mathrm{t}, 3 \mathrm{H}), 8.25(\mathrm{~d}, 1 \mathrm{H}), 8.09(\mathrm{~m}, 2 \mathrm{H}), 8.02(\mathrm{~d}, 1 \mathrm{H}), 7.94(\mathrm{~m}, 6 \mathrm{H})$, $7.77(\mathrm{~m}, 2 \mathrm{H}), 7.56(\mathrm{t}, 4 \mathrm{H}), 7.47(\mathrm{~m}, 4 \mathrm{H}), 7.29(\mathrm{~d}, 2 \mathrm{H}), 7.16(\mathrm{~d}, 1 \mathrm{H})$.

4.1.11 Synthesis of DPA-AP-TP [11]. Compound $10(1.0 \mathrm{~g}$, $1.4 \mathrm{mmol}$ ), diphenylamine (Aldrich, 98\%) (0.36 g, $2.1 \mathrm{mmol}$ ), $\mathrm{Pd}_{2}(\mathrm{dba})_{3}$ (Aldrich, 97\%) $(0.07 \mathrm{~g}, 0.07 \mathrm{mmol})$, sodium tetra butoxide (Aldrich, 97\%) (0.67 g, $7.0 \mathrm{mmol}$ ) were added to $100 \mathrm{~mL}$ of dry toluene solution. The reaction mixture was heated to $100{ }^{\circ} \mathrm{C}$ for $10 \mathrm{~h}$ under nitrogen. After the reaction was finished, chloroform and water were extracted. The organic layer was dried with anhydrous $\mathrm{MgSO}_{4}$ and filtered. The solvent was evaporated. The product was isolated by silica gel column chromatography using $\mathrm{CHCl}_{3}$ : hexane $(1: 5)$ eluent to afford a white solid (yield 68\%). ${ }^{1} \mathrm{H}-\mathrm{NMR}\left(300 \mathrm{MHz},\left[\mathrm{D}_{8}\right]\right.$ THF $25{ }^{\circ} \mathrm{C}$, TMS): 8.46 (d, 1H), 8.43 (d, 1H), $8.29(\mathrm{~m}, 4 \mathrm{H}), 8.19$ (d, 1H), 8.10 (d, 1H), $8.06(\mathrm{~m}, 1 \mathrm{H}), 7.94(\mathrm{~m}, 3 \mathrm{H}), 7.86(\mathrm{~d}, 4 \mathrm{H}), 7.49(\mathrm{t}, 4 \mathrm{H}), 7.40$ $(\mathrm{m}, 7 \mathrm{H}), 7.22(\mathrm{~m}, 10 \mathrm{H}), 6.91(\mathrm{~m}, 2 \mathrm{H}) . \mathrm{EI}^{+}$-mass: 773, HRMS (EI, $m / z):\left[\mathrm{M}^{+}\right]$calcd for $\mathrm{C}_{60} \mathrm{H}_{39} \mathrm{~N}_{1}, 773.3082$; found, 773.3080. Anal. calcd for $\mathrm{C}_{60} \mathrm{H}_{39} \mathrm{~N}_{1}$ : C 93.11, H 5.08, N 1.81; found: C 92.62, H $5.07, \mathrm{~N} 1.80 \%$.

4.1.12 Synthesis of TPA-AP-TP [12]. Compound $10(1.0 \mathrm{~g}$, $1.4 \mathrm{mmol}), \mathrm{Pd}\left(\mathrm{PPh}_{3}\right)_{4}$ (Aldrich, 99\%) (0.08 g, $\left.0.07 \mathrm{mmol}\right)$ were added to $100 \mathrm{~mL}$ of anhydrous toluene solution. Then, compound $3(0.61 \mathrm{~g}, 2.1 \mathrm{mmol})$ and $2 \mathrm{M} \mathrm{K}_{2} \mathrm{CO}_{3}$ solution $(8 \mathrm{~mL})$, which was dissolved in $\mathrm{H}_{2} \mathrm{O}$, was added to the reaction mixture. The reaction mixture was heated to $110{ }^{\circ} \mathrm{C}$ for $5 \mathrm{~h}$ under nitrogen. After the reaction was finished, chloroform and water were extracted. The organic layer was dried with anhydrous $\mathrm{MgSO}_{4}$ and filtered. The solvent was evaporated. The product was isolated by silica gel column chromatography using $\mathrm{CHCl}_{3}$ : hexane $(1: 4)$ eluent to afford a white solid. (Yield 76\%) ${ }^{1} \mathrm{H}$ NMR $\left(300 \mathrm{MHz},\left[\mathrm{D}_{8}\right]\right.$ THF $25{ }^{\circ} \mathrm{C}$, TMS): $\delta=8.46(\mathrm{~d}, 1 \mathrm{H}), 8.42$ (d, 1H), 8.29 (d, 2H), 8.18 (d, 1H), 8.07 (m, 2H), $7.86(\mathrm{~m}, 9 \mathrm{H})$, $7.49(\mathrm{t}, 5 \mathrm{H}), 7.37(\mathrm{~m}, 18 \mathrm{H}), 7.20(\mathrm{t}, 2 \mathrm{H}), 7.08(\mathrm{t}, 2 \mathrm{H}) . \mathrm{EI}^{+}$-mass: 849, HRMS (EI, $m / z$ ): $\left[\mathrm{M}^{+}\right]$calcd for $\mathrm{C}_{66} \mathrm{H}_{43} \mathrm{~N}_{1}$, 849.3395; found, 849.3393. Anal. calcd for $\mathrm{C}_{66} \mathrm{H}_{43} \mathrm{~N}_{1}$ : C 93.25, H 5.10, N 1.65; found: C 93.15, $\mathrm{H} 4.99, \mathrm{~N} 1.64 \%$.

4.1.13 Synthesis of compound [13]. 9.10-Dibromoanthracene (2.0 g, $5.9 \mathrm{mmol}), \mathrm{Pd}\left(\mathrm{PPh}_{3}\right)_{4}$ (Aldrich, 99\%) (0.2 g, $0.17 \mathrm{mmol}$ ) were added to $100 \mathrm{~mL}$ of anhydrous THF solution. Then, compound $5(2.1 \mathrm{~g}, 5.9 \mathrm{mmol})$ and $2 \mathrm{M} \mathrm{K}_{2} \mathrm{CO}_{3}$ solution ( $5 \mathrm{~mL}$ ), which was dissolved in $\mathrm{H}_{2} \mathrm{O}$, was added to the reaction mixture. The reaction mixture was heated to $65^{\circ} \mathrm{C}$ for $4 \mathrm{~h}$ under nitrogen. After the reaction was finished, chloroform and water were extracted. The organic layer was dried with anhydrous
$\mathrm{MgSO}_{4}$ and filtered. The solvent was evaporated. The product was isolated by silica gel column chromatography using $\mathrm{CHCl}_{3}$ : hexane (1:9) eluent to afford a white solid. (Yield 48\%) ${ }^{1} \mathrm{H}$ NMR (300 MHz, $\left.\mathrm{CDCl}_{3} 25{ }^{\circ} \mathrm{C}, \mathrm{TMS}\right): \delta=8.46(\mathrm{~d}, 1 \mathrm{H}), 8.64(\mathrm{~d}$, $2 \mathrm{H}), 8.03(\mathrm{~s}, 1 \mathrm{H}), 7.82(\mathrm{~d}, 2 \mathrm{H}), 7.72(\mathrm{~d}, 4 \mathrm{H}), 7.65(\mathrm{~m}, 2 \mathrm{H}), 7.60(\mathrm{~m}$, $2 \mathrm{H}), 7.42(\mathrm{~m}, 8 \mathrm{H})$.

4.1.14 Synthesis of compound [14]. Compound 13 (2 g, $4.1 \mathrm{mmol}$ ) was added in $100 \mathrm{~mL}$ of anhydrous THF solution and stirred at $-78{ }^{\circ} \mathrm{C}$, then $n$-butyllithium solution (Aldrich, 2.0 $\mathrm{M}$ in cyclohexane) $(2.1 \mathrm{~mL}$ ) was added. Next, triethyl borate (Aldrich, $99 \%)(1.5 \mathrm{~mL})$ was added to the reaction mixture after $30 \mathrm{~min}$. After the reaction had finished, $\mathrm{HCl} 35 \mathrm{wt} \%$ solution was added to the reaction mixture after $3 \mathrm{~h}$. The reaction mixture was extracted with diethyl ether and water. The organic layer was dried with anhydrous $\mathrm{MgSO}_{4}$ and filtered. The mixture was evaporated. The product was recrystallized from dichloromethane $\left(\mathrm{CH}_{2} \mathrm{Cl}_{2}\right)$ and hexane. (Yield 65\%). ${ }^{1} \mathrm{H}$ NMR $(300 \mathrm{MHz}$, $\left.\mathrm{CDCl}_{3}, 25{ }^{\circ} \mathrm{C}, \mathrm{TMS}\right): \delta=8.18(\mathrm{~d}, 2 \mathrm{H}), 8.01(\mathrm{~s}, 1 \mathrm{H}), 7.85(\mathrm{~d}, 2 \mathrm{H})$, $7.72(\mathrm{~d}, 4 \mathrm{H}), 7.64(\mathrm{~s}, 2 \mathrm{H}), 7.48(\mathrm{~m}, 6 \mathrm{H}), 7.36(\mathrm{~m}, 4 \mathrm{H}), 5.17(\mathrm{~s}, 2 \mathrm{H})$.

4.1.15 Synthesis of compound [15]. Compound $14(2.0 \mathrm{~g}$, $4.4 \mathrm{mmol}), \mathrm{Pd}\left(\mathrm{PPh}_{3}\right)_{4}$ (Aldrich, 99\%) (0.2 g, $\left.0.17 \mathrm{mmol}\right)$ were added to $200 \mathrm{~mL}$ of anhydrous toluene solution. Then, compound 2 ( $3.2 \mathrm{~g}, 8.8 \mathrm{mmol})$ and $2 \mathrm{M} \mathrm{K}_{2} \mathrm{CO}_{3}$ solution $(10 \mathrm{~mL})$, which was dissolved in $\mathrm{H}_{2} \mathrm{O}$, was added to the reaction mixture. The reaction mixture was heated to $85{ }^{\circ} \mathrm{C}$ for $3 \mathrm{~h}$ under nitrogen. After the reaction was finished, chloroform and water were extracted. The organic layer was dried with anhydrous $\mathrm{MgSO}_{4}$ and filtered. The solvent was evaporated. The product was isolated by silica gel column chromatography using $\mathrm{CHCl}_{3}$ : hexane (1:5) eluent to afford a white solid. (Yield 42\%) ${ }^{1} \mathrm{H}$ NMR (300 MHz, $\left.\mathrm{CDCl}_{3} 25{ }^{\circ} \mathrm{C}, \mathrm{TMS}\right): \delta=8.60(\mathrm{~d}, 1 \mathrm{H}), 8.48(\mathrm{~d}$, $1 \mathrm{H}), 8.38(\mathrm{~d}, 1 \mathrm{H}), 8.26(\mathrm{~d}, 1 \mathrm{H}), 8.15(\mathrm{~d}, 1 \mathrm{H}), 8.07(\mathrm{~s}, 1 \mathrm{H}), 7.95(\mathrm{~m}$, $3 \mathrm{H}), 7.88(\mathrm{~s}, 1 \mathrm{H}), 7.83(\mathrm{~m}, 6 \mathrm{H}), 7.52(\mathrm{~m}, 5 \mathrm{H}), 7.43(\mathrm{~m}, 6 \mathrm{H}), 7.22(\mathrm{t}$, $2 \mathrm{H})$.

4.1.16 Synthesis of TP-AP-DPA [16]. Compound $15(1.0 \mathrm{~g}$, $1.4 \mathrm{mmol}$ ), diphenylamine (Aldrich, 98\%) (0.36 g, $2.1 \mathrm{mmol}$ ), $\mathrm{Pd}_{2}(\mathrm{dba})_{3}$ (Aldrich, 97\%) (0.07 g, $\left.0.07 \mathrm{mmol}\right)$, sodium tetra butoxide (Aldrich, 97\%) were added to $100 \mathrm{~mL}$ of anhydrous toluene solution. The reaction mixture was heated to $100{ }^{\circ} \mathrm{C}$ for $10 \mathrm{~h}$ under nitrogen. After the reaction was finished, chloroform and water were extracted. The organic layer was dried with anhydrous $\mathrm{MgSO}_{4}$ and filtered. The solvent was evaporated. The product was isolated by silica gel column chromatography using $\mathrm{CHCl}_{3}$ : hexane $(1: 4)$ eluent to afford a white solid (yield 58\%). ${ }^{1} \mathrm{H}-\mathrm{NMR}\left(300 \mathrm{MHz},\left[\mathrm{D}_{8}\right]\right.$ THF $25{ }^{\circ} \mathrm{C}$, TMS): $8.42(\mathrm{~d}, 1 \mathrm{H})$, 8.30 (d, 1H), 8.19 (m, 3H), 8.09 (d, 1H), 7.90 (m, 10H), 7.49 (m, $4 \mathrm{H}), 7.37(\mathrm{~m}, 7 \mathrm{H}), 7.24(\mathrm{t}, 6 \mathrm{H}), 7.11(\mathrm{~d}, 4 \mathrm{H}), 6.97(\mathrm{t}, 2 \mathrm{H}) . \mathrm{EI}^{+}-$ mass: 773, HRMS (EI, $m / z):\left[\mathrm{M}^{+}\right]$calcd for $\mathrm{C}_{60} \mathrm{H}_{39} \mathrm{~N}_{1}, 773.3082$; found, 773.3092. Anal. calcd for $\mathrm{C}_{60} \mathrm{H}_{39} \mathrm{~N}_{1}$ : C 93.11, $\mathrm{H} 5.08, \mathrm{~N}$ 1.81; found: C 92.78, H 5.14, N 1.83\%.

4.1.17 Synthesis of TP-AP-TPA [17]. Compound 15 (1.0 g, $1.4 \mathrm{mmol}), \mathrm{Pd}\left(\mathrm{PPh}_{3}\right)_{4}$ (Aldrich, 99\%) (0.08 g, $\left.0.07 \mathrm{mmol}\right)$ were added to $100 \mathrm{~mL}$ of anhydrous toluene solution. Then, compound $3(0.8 \mathrm{~g}, 2.8 \mathrm{mmol})$ and $2 \mathrm{M} \mathrm{K}_{2} \mathrm{CO}_{3}$ solution $(5 \mathrm{~mL})$, which was dissolved in $\mathrm{H}_{2} \mathrm{O}$, was added to the reaction mixture. The reaction mixture was heated to $100{ }^{\circ} \mathrm{C}$ for $4 \mathrm{~h}$ under nitrogen. After the reaction was finished, chloroform and water 
were extracted. The organic layer was dried with anhydrous $\mathrm{MgSO}_{4}$ and filtered. The solvent was evaporated. The product was isolated by silica gel column chromatography using $\mathrm{CHCl}_{3}$ : hexane $(1: 4)$ eluent to afford a white solid. (Yield 62\%) ${ }^{1} \mathrm{H}$ NMR $\left(300 \mathrm{MHz},\left[\mathrm{D}_{8}\right]\right.$ THF $\left.25{ }^{\circ} \mathrm{C}, \mathrm{TMS}\right): \delta=8.42(\mathrm{~d}, 1 \mathrm{H}), 8.30$ $(\mathrm{d}, 1 \mathrm{H}), 8.18(\mathrm{~m}, 3 \mathrm{H}), 8.13(\mathrm{~d}, 1 \mathrm{H}), 7.93(\mathrm{~m}, 10 \mathrm{H}), 7.51(\mathrm{~m}, 4 \mathrm{H})$, $7.37(\mathrm{~m}, 7 \mathrm{H}), 7.22(\mathrm{t}, 6 \mathrm{H}), 7.11(\mathrm{~d}, 4 \mathrm{H}), 6.95(\mathrm{t}, 2 \mathrm{H}) . \mathrm{EI}^{+}$-mass: 849, HRMS (EI, $m / z$ ): $\left[\mathrm{M}^{+}\right]$calcd for $\mathrm{C}_{66} \mathrm{H}_{43} \mathrm{~N}_{1}$, 849.3395; found, 849.3390. Anal. calcd for $\mathrm{C}_{66} \mathrm{H}_{43} \mathrm{~N}_{1}$ : C 93.25, H 5.10, N 1.65; found: C 92.90, $\mathrm{H} 4.97, \mathrm{~N} 1.70 \%$.

\section{Conflicts of interest}

There are no conflicts to declare.

\section{Acknowledgements}

This research was supported by National R\&D Program through the National Research Foundation of Korea (NRF) funded by the Ministry of Science \& ICT (No. 2017M3A7B4041699). This research was supported by Basic Science Research Program through the National Research Foundation of Korea (NRF) funded by the Ministry of Education (No. 2017R1D1A1A09082138).

\section{Notes and references}

1 (a) C. W. Tang and S. A. Van Slyke, Appl. Phys. Lett., 1987, 51, 913; (b) Y. R. Sun, N. Giebink, C. Kanno, B. Ma, M. E. Thompson and S. R. Forrest, Nature, 2006, 440, 908; (c) M. F. Wu, S. J. Yeh, C. T. Chen, H. Murayama, T. Tsuboi, W. S. Li, I. Chao, S. W. Liu and J. K. Wang, Adv. Funct. Mater., 2007, 17, 1887; (d) Z. Zhao, C. Deng, S. Chen, J. W. Y. Lam, W. Qin, P. Lu, Z. Wang, H. S. Kwok, Y. Ma, H. Qiu and B. Z. Tang, Chem. Commun., 2011, 47, 8847; (e) H. Wu, G. Zhou, J. Zou, C. L. Ho, W. Y. Wong, W. Yang, J. Peng and Y. Cao, Adv. Mater., 2009, 21, 4181; $(f)$ M. C. Gather, A. Kohnen, A. Falcou, H. Becker and K. Meerholz, Adv. Funct. Mater., 2007, 17, 191; (g) J. Huang, X. Wang, A. J. deMello, J. C. deMello and D. D. C. Bradley, J. Mater. Chem., 2007, 17, 3551; $(h)$ B. Chen, J. Ding, L. Wang, X. Jing and F. Wang, Chem. Commun., 2012, 48, 8970; (i) Z. Shen, P. E. Burrows, V. Bulović, S. R. Forrest and M. E. Thompson, Science, 1997, 276, 2009; (j) S. R. Forrest, Org. Electron., 2003, 4, 45; (k) A. R. Duggal, J. J. Shiang, C. M. Heller and D. F. Foust, Appl. Phys. Lett., 2002, 80, 3470; (l) B. W. D'Andrade and S. R. Forrest, $A d v$. Mater., 2004, 16, 1585; $(\mathrm{m})$ M. Yu, S. Wang, S. Shao, J. Ding, L. Wang, X. Jing and F. Wang, J. Mater. Chem. C, 2015, 3, 861; (n) L. Zhao, S. Wang, S. Shao, J. Ding, L. Wang, X. Jing and F. Wang, J. Mater. Chem. C, 2015, 3, 8859; (o) S. Kim, B. Kim, J. Lee, H. Shin, Y.-I. Park and J. Park, Mater. Sci. Eng., R, 2016, 99, 1; (p) J. T. Smith, B. A. Katchman, D. E. Kullman, U. Obahiagbon, Y.-K. Lee, B. P. O'Brien, G. B. Raupp, K. S. Anderson and J. B. Christen, J. Disp. Technol., 2016, 12, 273; (q) B. A. Katchman, J. T. Smith, U. Obahiagbon, S. Kesiraju,
Y.-K. Lee, B. O'Brien, K. Kaftanoglu, J. B. Christen and K. S. Anderson, Sci. Rep., 2016, 6, 29057; (r) J. Ynag, J. Huang, Q. Li and Z. Li, J. Mater. Chem. C, 2016, 4, 2663.

2 (a) J. H. Jou, C. P. Wang, M. H. Wu, H. W. Lin, H. C. Pan and B. H. Liu, J. Mater. Chem., 2010, 20, 6626; (b) S. Krotkus, D. Kasemann, S. Lenk, K. Leo and S. Reineke, Light: Sci. Appl., 2016, 5, e16121; (c) E. Angioni, M. Chapran, K. Ivaniuk, N. Kostiv, V. Cherpak, P. Stakhira, A. Lazauskas, S. Tamulevičius, D. Volyniuk, N. J. Findlay, T. Tuttle, J. V. Grazulevicius and P. J. Skabara, J. Mater. Chem. C, 2016, 4, 3851; (d) H.-J. Kim, M.-H. Shin, H.-G. Hong, B.-S. Song, S.-K. Kim, W.-H. Koo, J.-G. Yoon, S.-Y. Yoon and Y.-J. Kim, J. Disp. Technol., 2016, 12, 526; (e) Y. Chen, J. Wang, Z. Zhong, Z. Jiang, C. Song, Z. Hu, J. Peng, J. Wang and Y. Cao, Org. Electron., 2016, 37, 458.

3 (a) Y. L. Chang, Y. Song, Z. Wang, M. G. Helander, J. Qiu, L. Chai, Z. Liu, G. D. Scholes and Z. Lu, Adv. Funct. Mater., 2013, 23, 705; (b) S. Reineke, F. Lindner, G. Schwartz, N. Seidler, K. Walzer, B. Lüssem and K. Leo, Nature, 2009, 459, 234; (c) M. Thomschke, S. Reineke, B. Lüssem and K. Leo, Nano Lett., 2012, 12, 424; (d) L. Zhou, X. Li, X. Li, J. Feng, S. Song and H. Zhang, J. Phys. Chem. C, 2010, 114, 21723; (e) H. P. Lin, F. Zhou, J. Li, X. W. Zhang, L. Zhang, X. Y. Jiang, Z. L. Zhang and J. H. Zhang, J. Phys. Chem. C, 2011, 115, 24341; $(f)$ S. A. Wang, W. Y. Hung, Y. H. Chen and K. T. Wong, Org. Electron., 2012, 13, 1576; $(g)$ Z. Wu, J. Luo, N. Sun, L. Zhu, H. Sun, L. Yu, D. Yang, X. Qiao, J. Chen, C. Yang and D. Ma, Adv. Funct. Mater., 2016, 26, 3306.

4 (a) X. Yang, H. Huang, B. Pan, M. P. Aldred, S. Zhuang, L. Wang, J. Chen and D. Ma, J. Phys. Chem. C, 2012, 116, 15041; (b) L. Duan, D. Zhang, K. Wu, X. Huang, L. Wang and Y. Qiu, Adv. Funct. Mater., 2011, 21, 3540; (c) S. M. Shen, Y. C. Tsai and J. H. Jou, ACS Appl. Mater. Interfaces, 2011, 3, 3134; (d) X. Yang, Y. Zhao, X. Zhang, R. Li, J. Dang, Y. Li, G. Zhou, Z. Wu, D. Ma, W. Y. Wong, X. Zhao, A. Ren, L. Wang and X. Hou, J. Mater. Chem., 2012, 22, 7136; (e) R. Springer, B. Y. Kang, R. Lampande, D. H. Ahn, S. Lenk, S. Reineke and J. H. Kwon, Opt. Express, 2016, 24, 28131; (f) M. Du, Y. Feng, D. Zhu, T. Peng, Y. Liu, Y. Wang and M. R. Bryce, Adv. Mater., 2016, 28, 5963.

5 (a) N. C. Giebink, B. W. D'Andrade, M. S. Weaver, P. B. Mackenzie, J. J. Brown, M. E. Thompson and S. R. Forrest, J. Appl. Phys., 2008, 103, 44509; (b) I. R. de Moraes, S. Scholz, B. Lussem and K. Leo, Org. Electron., 2011, 12, 341; (c) H. Shin, H. Jung, B. Kim, J. Lee, J. Moon, J. Kim and J. Park, J. Mater. Chem. C, 2016, 4, 3833; (d) S. Lee, B. Kim, H. Jung, H. Shin, H. Lee, J. Lee and J. Park, Dyes Pigm., 2016, 136, 255.

6 (a) S.-H. Lin, F.-I. Wu and R.-S. Liu, Chem. Commun., 2009, 6961; (b) K. Danel, T.-H. Huang, J. T. Lin, Y.-T. Tao and C.-H. Chuen, Chem. Mater., 2002, 14, 3860; (c) C.-H. Chien, C.-K. Chen, F.-M. Hsu, C.-F. Shu, P.-T. Chou and C.-H. Lai, Adv. Funct. Mater., 2009, 19, 560; (d) C. J. Zheng, W. M. Zhao, Z. Q. Wang, D. Huang, J. Ye, X. M. Ou, X. H. Zhang, C. S. Lee and S. T. Lee, J. Mater. Chem., 2010, 
20, 1560; (e) C. H. Wu, C. H. Chien, F. M. Hsu, P. I Shih and C. F. Shu, J. Mater. Chem., 2009, 19, 1464; (f) C. J. Kuo, T. Y. Li, C. C. Lien, C. H. Liu, F. I. Wu and M. J. Huang, J. Mater. Chem., 2009, 19, 1865; (g) S. K. Kim, B. Yang, Y. Ma, J. H. Lee and J. Park, J. Mater. Chem., 2008, 18, 3376; (h) H. Shin, H. Kang, B. Kim, Y. Park, Y. J. Yu and J. Park, Bull. Korean Chem. Soc., 2014, 35, 3041; (i) Z. Li, Y. Sun, H. Li, J. Ren, C. Si, X. Lv, J. Yu, H. Wang, F. Shi and Y. Hao, Synth. Met., 2016, 217, 102; (j) X. Wei, L. Bu, X. Li, H. Ågren and Y. Xie, Dyes Pigm., 2017, 136, 480; (k) J. Y. Song, S. N. Park, S. J. Lee, Y. K. Kim and S. S. Yoon, Dyes Pigm., 2015, 114, 40.

7 (a) S. L. Lai, Q. X. Tong, M. Y. Chan, T. W. Ng, M. F. Lo, S. T. Lee and C. S. Lee, J. Mater. Chem., 2011, 21, 1206; (b) T. M. Figueira-Duarte, P. G. D. Rosso, R. Trattnig, S. Sax, E. J. W. List and K. Mullen, Adv. Mater., 2010, 22, 990; (c) K.-C. Wu, P.-J. Ku, C.-S. Lin, H.-T. Shih, F.-I. Wu, M.-J. Huang, J.-J. Lin, I.-C. Chen and C.-H. Cheng, Adv. Funct. Mater., 2008, 18, 67; (d) M. Y. Lo, C. Zhen, M. Lauters, G. E. Jabbour and A. Sellinger, J. Am. Chem. Soc., 2007, 129, 5808; (e) K. R. Justin Thomas, N. Kapoor, M. N. K. Prasad Bolisetty, J.-H. Jou, Y.-L. Chen and Y.-C. Jou, J. Org. Chem., 2012, 77, 3921; (f) A. Islam, Q. Wang, L. Zhang, T. Lei, L. Hong, R. Yang, Z. Liu, R. Peng, L.-S. Liao and Z. Ge, Dyes Pigm., 2017, 142, 499; $(g)$ D. Karthik, K. R. J. Thomas, J.-H. Jou, S. Kumar, Y.-L. Chen and Y.-C. Jou, RSC Adv., 2015, 5, 8727.

8 (a) E. J. W. List, R. Guentner, P. Scanducci de Freitas and U. Scherf, Adv. Mater., 2002, 14, 374; (b) M. S. Gong, H. S. Lee and Y. M. Jeon, J. Mater. Chem., 2010, 20, 10735; (c) Y. M. Jeon, J. Y. Lee, J. W. Kim, C. W. Lee and M. S. Gong, Org. Electron., 2010, 11, 1844; (d) S. O. Jeon, Y. M. Jeon, J. W. Kim, C. W. Lee and M. S. Gong, Org. Electron., 2008, 9, 522; (e) K.-T. Wong, R.-T. Chen, F.-C. Fang, C.-C. Wu and Y.-T. Lin, Org. Lett., 2005, 7, 1979; (f) S. S. Reddy, V. G. Sree, K. Gunasekar, W. Cho, Y.-S. Gal, M. Song, J.-W. Kang and S.-H. Jin, Adv. Opt. Mater., 2016, 4, 1236; $(g)$ S. S. Reddy, V. G. Sree, W. Cho and S.-H. Jin, Chem.-Asian J., 2016, 11, 3275.

9 (a) L. Wang, Z. Y. Wu, W. Y. Wong, K. W. Cheah, H. Huang and C. H. Chen, Org. Electron., 2011, 12, 595; (b) J. K. Park, K. H. Lee, S. Kang, J. Y. Lee, J. S. Park, J. H. Seo, Y. K. Kim and S. S. Yoon, Org. Electron., 2010, 11, 905; (c) J. Y. Hu, Y. J. Pu, F. Satoh, S. Kawata, H. Katagiri, H. Sasabe and J. Kido, Adv. Funct. Mater., 2014, 24, 2064; (d) C. L. Wu, C. H. Chang, Y. T. Chang, C. T. Chen, C. T. Chen and C. J. Su, J. Mater. Chem. C, 2014, 2, 7188.

10 (a) D. Bailey and V. E. Williams, Chem. Commun., 2005, 2569; (b) Y. Zhang, G. Cheng, Y. Zhao, J. Y. Hou, S. Y. Liu, S. Tang and Y. G. Ma, Appl. Phys. Lett., 2005, 87, 241112; (c) S. Tang, M. Liu, P. Lu, G. Cheng, M. Zeng, Z. Q. Xie, H. Xu, H. P. Wang, B. Yang, Y. G. Ma and D. H. Yan, Org. Electron., 2008, 9, 241; (d) C.-C. Wu, Y.-T. Lin, K.-T. Wong, R.-T. Chen and Y.-Y. Chien, Adv. Mater., 2004, 16, 61; (e) J. H. Jou, M. H. Wu, C. P. Wang, Y. S. Chiu, P. H. Chiang, H. C. Hu and R. Y. Wang, Org. Electron., 2007, 8, 735; $(f)$ S. Tang, W. J. Li, F. Z. Shen, D. D. Liu, B. Yang and Y. G. Ma, J. Mater. Chem., 2012, 22, 4401; (g) S. Tao, Y. l. Jiang, S. L. Lai, M. K. Fung, Y. C. Zhou, X. H. Zhang, W. M. Zhao and C. S. Lee, Org. Electron., 2011, 12, 358.

11 B. Kim, Y.-I. Park, J. Lee, D. Yokoyama, J. H. Lee, J. Kido and J. Park, J. Mater. Chem. C, 2013, 1, 432.

12 (a) H. Lee, B. Kim, S. Kim, J. Kim, J. Lee, H. G. Shin, J. H. Lee and J. Park, J. Mater. Chem. C, 2014, 2, 4737; (b) K. Sumi, Y. Niko, K. Tokumaruz and G. Konishi, Chem. Commun., 2013, 49, 3893; (c) Z. Gao, Z. Wang, T. Shan, Y. Liu, F. Shen, Y. Pan, H. Zhang, X. He, P. Lu, B. Yang and Y. Ma, Org. Electron., 2014, 15, 2667; (d) Q. Zhang, H. Kuwabara, W. J. Potscavage Jr, S. Huang, Y. Hatae, T. Shibata and C. Adachi, J. Am. Chem. Soc., 2014, 136, 18070. 13 (a) Y. Park, B. Kim, C. Lee, A. Hyun, S. Jang, J. H. Lee, Y. S. Gal, T. H. Kim, K. S. Kim and J. Park, J. Phys. Chem. $C$, 2011, 115, 4843; (b) S. Ye, J. Chen, C. Di, Y. Liu, K. Lu, W. Wu, C. Du, Y. Liu, Z. Shuai and G. Yu, J. Mater. Chem., 2010, 20, 3186.

14 Y. Park, J. H. Lee, D. H. Jung, S. H. Liu, Y. H. Lin, L. Y. Chen, C. C. Wu and J. Park, J. Mater. Chem., 2010, 20, 5930.

15 M. J. Frisch, G. W. Trucks, H. B. Schlegel, G. E. Scuseria, M. A. Robb, J. R. Cheeseman, G. Scalmani, V. Barone, B. Mennucci, G. A. Petersson, H. Nakatsuji, M. Caricato, X. Li, H. P. Hratchian, A. F. Izmaylov, J. Bloino, G. Zheng, J. L. Sonnenberg, M. Hada, M. Ehara, K. Toyota, R. Fukuda, M. I. J. Hasegawa, T. Nakajima, Y. Honda, O. Kitao, H. Nakai, T. Vreven, J. A. Montgomery Jr, J. E. Peralta, F. Ogliaro, M. Bearpark, J. J. Heyd, E. Brothers, K. N. Kudin, V. N. Staroverov, R. Kobayashi, J. Normand, K. Raghavachari, A. Rendell, J. C. Burant, S. S. Iyengar, J. Tomasi, M. Cossi, N. Rega, J. M. Millam, M. Klene, J. E. Knox, J. B. Cross, V. Bakken, C. Adamo, J. Jaramillo, R. Gomperts, R. E. Stratmann, O. Yazyev, A. J. Austin, R. Cammi, C. Pomelli, J. W. Ochterski, R. L. Martin, K. Morokuma, V. G. Zakrzewski, G. A. Voth, P. Salvador, J. J. Dannenberg, S. Dapprich, A. D. Daniels, Ö. Farkas, J. B. Foresman, J. V. Ortiz, J. Cioslowski and D. J. Fox, Gaussian 09, Revision D. 01, Gaussian, Inc., Wallingford, CT, 2009. 